\title{
Building a New Urban Highway or Elevating an Old One? Finding Optimum Solution Based on Environmental Impacts
}

\author{
Rahil Farhani ${ }^{1}$, Seyed Navid Mashhadi Moghadam ${ }^{2, *}$, Maryam Shoaei Zangir ${ }^{3}$ \\ ${ }^{1}$ Department of Urban Design, Faculty of Art and Architecture, Hamedan Branch, Islamic Azad University, Hamedan, Iran \\ ${ }^{2}$ Faculty of Art and Architecture, University of Tarbiat Modares, Tehran, Iran \\ ${ }^{3}$ Department of Civil Engineering and Architecture, University of Art, Esfahan, Iran \\ *Corresponding author: navid.m.moghadam@hotmail.com
}

\begin{abstract}
For a sustainable urban expressway development, it is necessary to conduct an EIA (Environmental Impact Assessment) study. Expressway development and operation should, therefore, be planned with careful consideration of the environmental impacts. An assessment of an expressway project may include consideration of different routes as distinct alternatives. Thus, evaluating alternatives is an important step of environmental impact assessment. In this paper, some MCDM (Multi Criteria Decision Making) models, were used for assessing alternatives in EIA in earlier studies, reviewed and a hybrid MCDM model proposed to tackle the dependency relations of evaluation criteria with aid of the fuzzy DEMATEL (decision-making trial and evaluation laboratory) method. In next step, the fuzzy DEMATEL method combined with ANP (Analytic Network Process) method to weighting criteria for assessment of alternatives with aid of the fuzzy VIKOR (VIseKriterijumska Optimizacija I Kompromisno Resenje) method. Empirical study results illustrate the proposed model is a workable and reliable tool for evaluating alternatives of environmental impact assessment of urban expressway in order to make results much closer to reality.
\end{abstract}

Keywords: urban expressway, EIA, fuzzy DEMATEL combined with ANP, fuzzy VIKOR and MCDM model

Cite This Article: Rahil Farhani, Seyed Navid Mashhadi Moghadam, and Maryam Shoaei Zangir, "Building a New Urban Highway or Elevating an Old One? Finding Optimum Solution Based on Environmental Impacts." American Journal of Civil Engineering and Architecture, vol. 5, no. 4 (2017): 136-153. doi: 10.12691/ajcea-5-4-2.

\section{Introduction}

\subsection{What is Environmental Impact Assessment}

Sustainable development is the result of carefully integrating environmental, economic, and social needs to achieve both an increased standard of living in the short term, and a net gain or equilibrium between human, natural, and lucrative resources to support future generations [1].

By establishing a National Environmental Policy Act in 1970, The USA became first country to respond to concerns for pollutions, quality of life, loss of natural resources and environmental stress [2]. After that, many countries enact legislation on Environmental Impact Assessment (EIA) such as Australia (1974), Thailand (1975), France (1976), Philippines (1978), Italy (1986) and Pakistan (1992) [3]. EIA is a multi-step process by which a wide range of issues taken into account to determine whether and/or under which environmental constraints a project should be undertaken. The effectiveness of the EIA system is dependent on the specific steps involved in reviewing project proposals. In general, the major steps in the EIA process (shown in Figure 1) are: 1) Screening; 2) Scoping; 3) Examination of alternatives; 4) Impact Analysis; 5) Mitigation and impact management; 6) Evaluation of significance; 7) EIS report; 8) Review of EIS [4].

\subsection{Why do Expressway Development Projects Need Environmental Impact Assessment}

Development of expressway projects generally intended to improve the economic and social welfare of the people. At the same time, it may also create adverse impact on the surrounding environment for example People and properties may be in the direct path of road works are affected. The environmental impacts of expressway projects include damage to sensitive eco-systems, soil erosion, changes to drainage pattern and thereby ground water, interference with wild life movement, loss of productive agricultural lands, resettlement of people, disruption of local economic activities, demographic changes and accelerated urbanization [5]. Thus For a sustainable urban expressway development, it is necessary to conduct an EIA study. Expressway development and operation should, be planned with careful consideration of the environmental impacts. To minimize these adverse 
effects that may create by the expressway development projects, the techniques of EIA become necessary.

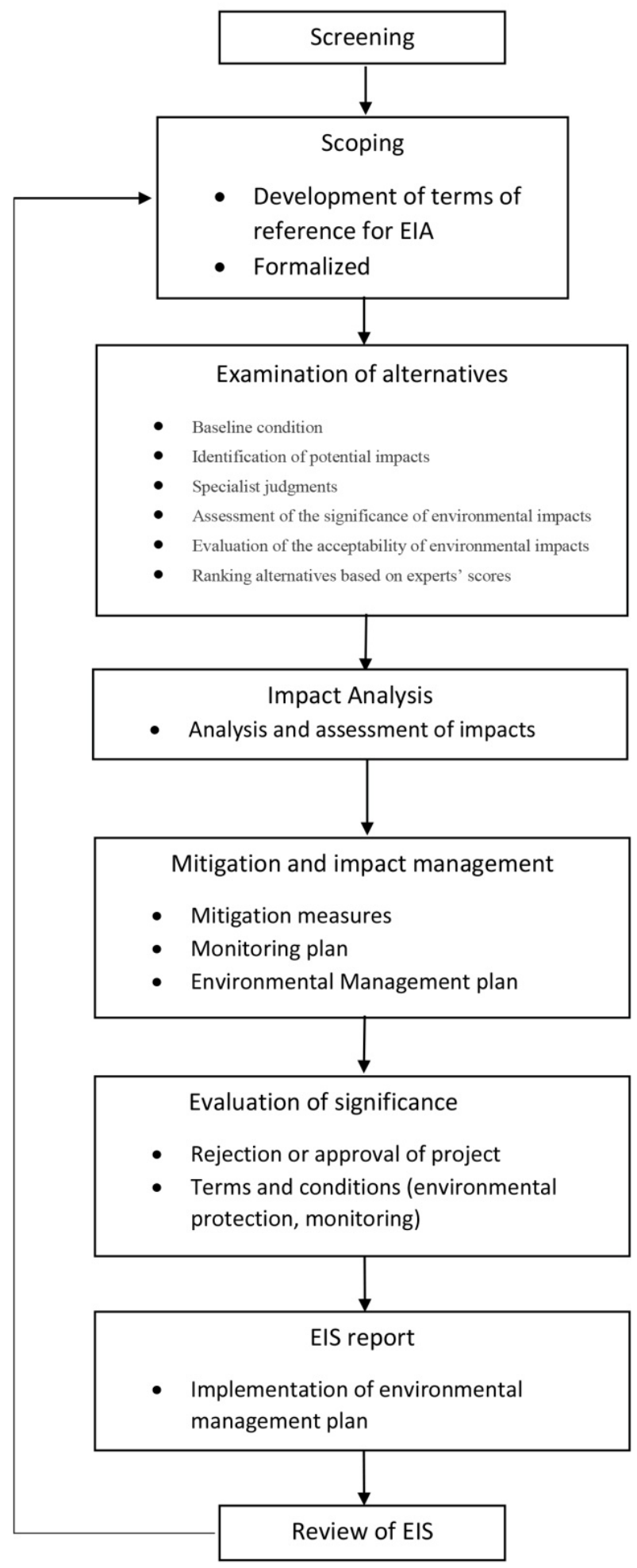

Figure 1. EIA process [4]

\subsection{What is Importance of Evaluating Alternatives in EIA of Expressway Projects}

Identification and assessment of potential environmental impact should be an integral part of the project cycle. It should commence early in the planning process to enable a full consideration of alternatives, and to avoid later delays and complications. Socio-political, environmental, and economic value judgments characterize environmental planning and decision-making and often make analysis more complicated. On the other hand, several alternatives should be found and evaluated in terms of many different criteria, resulting into a vast body of data that are sometimes inaccurate or uncertain [6].

\subsection{How can Evaluate Alternatives in EIA of Expressway Projects}

Multi-criteria decision-making can provide an ideal framework for EIA, which involves trade-off among various environmental problems and development. It also ensures accuracy in the sense that it has an inbuilt method to check the inconsistency of judgments [7]. Examination of alternatives includes decision-support tools for decision-makers to assess alternatives in order to find out optimum solutions. Several decision-support methods have discussed in literature review. Some of the methods are hybrid models and combined with other MCA (Multi Criteria Analysis) or MCDM (Multi Criteria Decision Making) methods, and some of the studies used only one method. For example, [8] introduced new hybrid MCDM method named evaluation framework of environmental impacts and costs of transport initiatives, which is a combination of the AHP with cost-benefit analysis methods to produce an impact's assessment of transport initiatives over different region sites and time periods. [9] devoted themselves to illustrate the use of the Analytical Hierarchy Process (AHP) as a decision support model to help managers understand the trade-offs between environmental dimensions.

\subsection{What is Objective of This Study}

Innovations and methodologies may need to improve the EIA process. In fact, the process of EIA has been evolving ever since it was adopted for analyzing the environmental impacts of developmental projects [7].

The purpose of this paper is to establish a new evaluation model in EIA with consideration of interrelations and dependency among criteria. Based on few evaluation criteria considered for EIA, this paper used several methods to establish the evaluation model. Fuzzy logic is a multi-valued logic, which introduced by Zadeh in order to deal with vague and indecisive ideas. The advantage of fuzzy logic is its aptitude to deal with nonlinearities and uncertainties. DEMATEL [10] shows the interrelations and dependency among criteria, finds total influential matrix and produces the network relations map which represents cause/effect groups. The final product of fuzzy DEMATEL illustrates a contextual relation between the elements within the system, in which a numeral represents the strength of influence. Then based on fuzzy DEMATEL combined with ANP method final weights of criteria will obtained. Finally, fuzzy VIKOR method, based on central weights obtained from fuzzy DEMATEL and ANP, employed to sort alternatives from the best to the worst according to S, R and Q score of alternatives.

The empirical study of this paper demonstrated with two alternatives for solving heavy vehicles' traffic issue. 
The proposed model could used to evaluate performances by considering fuzziness of subjective perception, illustrating criteria interrelations, and calculating gaps between proposed alternatives and ideal solution and finding closest one to the ideal scenario. Moreover, the results show that the optimum alternative obtained by the proposed model is consistent with that from traditional methods.

\section{Literature Review}

\subsection{Use of MCDM Models in Environmental Impact Assessment}

History of environmental assessment in the western countries began in 1969, with adoption of National Environmental Policy Act by Congress of the United States, and after that EIA implemented by many studies in both developed and developing countries [5,11,12,13,14]. By the end of the 1980-ies, number of researchers started development of special procedures and new contents for environmental impact assessment such as ecological framework and social impact assessment [15,16,17]. Meanwhile, numerous researches developed methodology of environmental impact assessment, for example, synthesis Weight [18] Artificial Aggregate Systems [19,20] MCDM and MCDA approaches [21-27] Risk Assessment [28,29,30] AHP, ANP and fuzzy logic [7,31,32,33,34,35].

Evans [36] analyzed decision-making process in the environmental impact assessment, which used by government agencies to approve or reject that have the significant impact on the environment. For solving problems of environmental impact assessment, which can cause by uncertainties of human judgments such as ignorance and fuzziness, [37] used the new analytical evidential reasoning (ER) algorithm for decision-making process through the real-world situation. [27] used Fuzzy Analytical Hierarchy Process to prioritize criteria in the assessment of various wind power plants and with using the weights of the selection criteria according to results of FAHP, they evaluated the wind-energy production alternatives located in Marmara region of Turkey [27]. [28] combined state-of-the-art research in MCDA methods applicable to nanotechnology with a hypothetical case study for nanomaterial management then illustrated MCDA application effects on balancing societal benefits against unintended side effects and risks. To manage the dependences among environmental factors [38] proposed a hybrid approach FANP (fuzzy analytic network process) as an integrated decision-support framework.

\subsection{Methods Used To Choosing Suitable Alternative in Expressway Development Projects}

In most EIA reports for highway/expressway development the procedure of choosing suitable alternative include following steps: finding out different routes options (including no project option), building description of each alternative environment, debate on advantages and disadvantages of each alternatives and choosing preferred alternative based on public opinions and experts consultation [39-44].

\subsection{Utility of Proposed Hybrid Model in Scientific Researches}

Yang, Shieh, and Tzeng [45] used VIKOR technique based on DEMATEL and ANP to propose hybrid model for information security risk-control assessment. Their research results show that proposed model can be effective in helping information technology managers validate the effectiveness of their risk controls. Also [46] employed hybrid MCDM model combining DEMATEL and ANP (DANP) with VIKOR in order to showing best selection to conduct the recycled materials for enhancing efficiency of using resources in the manufacturing process. [47] combined DEMATEL and ANP with VIKOR to improving strategies to reduce the gaps in customers satisfaction caused by interdependence and feedback problems among dimensions and criteria to achieve the aspiration level. [48] devoted themselves to clarify the interrelated relationships of brand marketing and find the problems or gaps and evaluated the situation to reduce the gaps in order to achieve the aspired levels and rank the priorities in brand marketing strategies by using a combination of DEMATEL,, ANP and VIKOR.

The proposed model in this paper has advantages against MCDM methods used for environmental impact assessment; these advantages include:

For fuzzy logic: The main advantage of Fuzzy Logic analysis was its ability to quickly process the subsequent survey responses and produce a ranked list for decision taking. In logic, there are sequences of statements, which are either 0 or 1 . Fuzzy Set Theory presents a framework to model the problem in an uncertainty environment. It is a mathematical method to handle uncertainty, as well as it supplies the technology to deal with details and accuracy of information so fuzzy set theory when in decision making problem related to complicating systems, the judgment by experts is determined in lingual expression for qualitative criteria instead of crisp values, these evaluations are vague and make analysis more difficult to compute. In many respects, fuzzy numbers depict the physical world more realistically than single-valued numbers.

Fuzzy DEMATEL combined with ANP (DANP): This study combined DEMATEL and ANP to evaluate a feasible information system implementation model. The two methods are widely applied as they can effectively solve the dependency of criteria and provide quantified decision making models to help decision makers in the selection of the ideal plan for maximum effects and effectiveness.

Fuzzy VIKOR: Among MCDM models, Techniques for Order Preference by Similarity to an Ideal Solution (TOPSIS) and VIKOR method are suitable for assessing related problems, provide excellent results close to reality, and grant superior analysis TOPSIS is similar to VIKOR; TOPSIS was chosen as an alternative that should have the shortest distance from the positive perfect solution (PIS) and the farthest from the negative-ideal solution (NIS) for solving a multiple-criteria decision-making problem [49]. There are advantages for VIKOR method include: Utility weight doesn't be used in TOPSIS method; alternatives are ranked by distance to ideal solution, while utility weight $\mathrm{v}$ is introduced to VIKOR method, and the attitude 
of decision-makers can be reflected by adjusting the value of v. TOPSIS method considers majority, while VIKOR method not only considers majority and also a minimum of an individual regret. Finally, TOPSIS method introduces weights to calculate distance to ideal solution, whereas VIKOR method doesn't make use of utility weight (v) until calculate $\mathrm{Si}$ and $\mathrm{Ri}$, which can enhance the veracity of results.

\subsection{Finding Criteria for Evaluating Alternatives of Expressway Project in EIA}

In next step, some studies about EIA of urban expressway reviewed in order to find out criteria to assess alternatives. An examination of environmental impacts of an expressway in Vietnam classified impacts in three groups, which are impacts during Pre-Construction, impacts during construction and impacts during operation. In researching for potential environmental impacts during construction time, three distinct cluster was identified as physical impacts, ecological impacts and social and cultural impacts. There were air quality, noise and vibration, water and soil pollution, waste, erosion, traffic safety, transportation of hazardous and dangerous materials and social impacts that has been evaluated for impacts during operation as the last part of evaluating before commencing the part of monitoring plan in that research. Results of that research showed that project required the acquisition of land for construction with ensuing social impacts related to resettlement and disturbances to settled patterns of life [44].

Another report that has been aimed to assess environmental impacts of a highway project evaluated impacts based on community impacts, construction impacts and cumulative and induced impacts, which are included land acquisition, relocation of houses and livelihood impacts for community impacts and for impacts on community infrastructure that study assessed noise impacts and safety and connectivity and nuisances from construction. At the end that report used habitat fragmentation, degradation and loss, decreases in the quality and quantity of soils, air emissions resulting in degradation of regional air quality, long range transport of air pollutants resulting in ecosystem acidification or eutrophication, loading large water bodies with discharges of sediment, thermal, and toxic pollutants, and social, economic, or cultural effects on low-income or minority communities resulting from ongoing development for progressive and induced impacts [50].

Most frequent factors, for assessing environmental impacts of an expressway development project, include: Air quality, Noise and vibration, water and soil pollution, waste, erosion, land acquisition, resettlement, traffic safety, problems of restricted access, impacts on regional investment growth, employment, time efficiency, aesthetic and architectural values, right of way and parks and recreation spaces [39,40,42,43,44,51,52].

Criteria for evaluating of an urban expressway obtained by reviewing four environmental impact reports and two articles and one guideline book [41,52-57] and shown as Table 1.

Table 1. Criteria for urban highway environmental impact assessment

\begin{tabular}{|c|c|c|}
\hline \# & Dimensions/Criteria & Description \\
\hline A & $\begin{array}{l}\text { Social environment } \\
\text { (a1) Social justice } \\
\text { (a2) Relocation of houses } \\
\text { (a3) Safety and Security } \\
\text { (a4) Restricted access problems }\end{array}$ & $\begin{array}{l}\text { Equitable distribution of services } \\
\text { Local coherence } \\
\text { The incidence of crime } \\
\text { Pedestrian safety }\end{array}$ \\
\hline B & $\begin{array}{l}\text { Spatial environment } \\
\text { (b1) Public utilities } \\
\text { (b2) Traffic Management } \\
\text { (b3) Land acquisition }\end{array}$ & $\begin{array}{l}\text { Strengthen of local structure } \\
\text { Legibility } \\
\text { Ease of implementation } \\
\text { Meet the capacity needs and passages' Level of service } \\
\text { Variation in transport models }\end{array}$ \\
\hline $\mathrm{C}$ & $\begin{array}{l}\text { Visual environment } \\
\left(\mathrm{c}_{1}\right) \text { Aesthetic and architectural values } \\
\left(\mathrm{c}_{2}\right) \text { Landscape and visual appearance }\end{array}$ & $\begin{array}{l}\text { Aesthetic and architectural values } \\
\text { Landscape and visual appearance }\end{array}$ \\
\hline $\mathrm{D}$ & $\begin{array}{l}\text { Economic environment } \\
\text { (d1) Employment } \\
\text { (d2) Land and real estate prices } \\
\text { (d3) The investment in the region } \\
\text { (d4) Time saving }\end{array}$ & $\begin{array}{l}\text { Employment and Unemployment } \\
\text { Income residents and shopkeepers } \\
\text { Land and real estate prices } \\
\text { The investment within the region }\end{array}$ \\
\hline $\mathrm{E}$ & $\begin{array}{l}\text { Physical and chemical environment } \\
\left(\mathrm{e}_{1}\right) \text { Air pollution } \\
\left(\mathrm{e}_{2}\right) \text { Surface Water pollution } \\
\left(\mathrm{e}_{3}\right) \text { Noise pollution } \\
\left(\mathrm{e}_{4}\right) \text { Environmental damage }\end{array}$ & $\begin{array}{l}\text { Air pollution from construction } \\
\text { Air pollution and smoke and gas infrastructure rising from asphalt } \\
\text { Excavation of material suspended in water resources and quality of water resources } \\
\text { Leaking fuel machines } \\
\text { Construction noise } \\
\text { Traffic Noise Pollution } \\
\text { Traffic Noise Pollution } \\
\text { Demolition of structures } \\
\text { Aggregation and accumulation of garbage and construction waste from construction } \\
\text { Aggregation and accumulation of garbage and construction waste from construction }\end{array}$ \\
\hline
\end{tabular}

Source (Authors adopted by Economic Reconstruction Agency, January 2012; Kaya \& Kahraman, 2011; B. N. Lohani et al., 1997; Modi \& Shinkar, 2012; National Highway Authority, July 2007; TRANSJAMAICAN HIGHWAY, September, 2007; Viet Nam Expressway Corporation, September 2010.). 


\section{Method}

\subsection{The Fuzzy DEMATEL Method Combined with ANP Method}

The DEMATEL method is a methodology, which can be used for researching and solving complicated and intertwined problem groups. The product of the DEMATEL process is a visual representation, the network relations map, by which respondents organize their own actions in the world. The most important property of the DEMATEL method used in the multi-criteria decision making (MCDM) field is to construct interrelations between criteria. It can clearly see the cause-effect relationship of criteria when measuring a problem. The DEMATEL method gathers collective-knowledge to capture the causal relationships between strategic criteria. The model is especially practical and useful for visualizing the structure of complicated causal relationships with matrices or digraphs $[58,59,60]$. When establishing a structural model, human judgments for deciding the relationship between systems (or sub-systems) are usually given by crisp values. However, in many cases, crisp values are inadequate in the real world. Human judgments with preferences are often unclear and hard to estimate by exact numerical values has created the need for fuzzy logic. The concept of Fuzzy Logic (FL) was conceived by Lotfi Zadeh and presented not as a control methodology, but as a way of processing data by allowing partial set membership rather than crisp set membership or nonmembership. In 1973, Professor Lotfi Zadeh proposed the concept of linguistic or "fuzzy" variables. The fuzzy DEMATEL turns the uncertain evaluations into triangular fuzzy numbers (see Table 2). Suppose that $\widetilde{A}$ and $\widetilde{B}$ are two triangular fuzzy numbers (TFN) parameterized by the triplet (a1, a2, a3) and (b1, b2, b3), respectively, the operational laws of these two triangular fuzzy numbers are as follows:

$$
\begin{aligned}
& \tilde{A} \oplus \tilde{B}=\left(a_{1}+b_{1}, a_{2}+b_{2}, a_{3}+b_{3}\right), \\
& \tilde{A} \ominus \tilde{B}=\left(a_{1}-b_{1}, a_{2}-b_{2}, a_{3}-b_{3}\right), \\
& \tilde{A} \otimes \tilde{B}=\left(a_{1} \times b_{1}, a_{2} \times b_{2}, a_{3} \times b_{3}\right),
\end{aligned}
$$

$$
\frac{\tilde{A}}{\tilde{B}}=\left(a_{1} / b_{1}, a_{2} / b_{2}, a_{3} / b_{3}\right) .
$$

The purpose of using the fuzzy DEMATEL in this paper is the analysis intertwined relations and dependency among criteria, so the direction and intensity of direct/indirect relationships lead to cause/effect grouping criteria and mapping network relations. Another reason for using fuzzy DEMATEL in this paper is the opportunity to combining with ANP so weights of criteria can be calculated easily and be applied in fuzzy VIKOR.

In a normal process of DEMATEL technique presented in 1973 results of the expert judgment show raw matrix Z which is normalized by dividing to maximum value of sum of each rows through Eq. (1) and (2).

$$
Z=\left[\begin{array}{ccccc}
z_{C}^{11} & \ldots & z_{C}^{1 j} & \ldots & z_{C}^{1 n} \\
\vdots & & \vdots & & \vdots \\
z_{C}^{i 1} & \ldots & z_{C}^{i j} & \ldots & z_{C}^{i n} \\
\vdots & & \vdots & & \vdots \\
z_{C}^{n 1} & \ldots & z_{C}^{n j} & \ldots & z_{C}^{n n}
\end{array}\right]
$$

where $r=\max _{i} \sum_{j=1}^{n} Z_{c}^{i j}, i, j \in\{1,2, \ldots, n\}$.

Then total-influential matrix $\mathrm{T}$ can be obtained from Eq. (3), in which I denotes the identity matrix,

\begin{tabular}{|c|c|c|c|c|c|c|c|c|}
\hline Criterira & $\mathrm{A} 1$ & A2 & A3 & B1 & $\mathrm{B} 2$ & C1 & $\mathrm{C} 2$ & $\widetilde{D}_{i}$ \\
\hline A1 & $\tilde{t}_{c}^{11}$ & $\tilde{t}_{c}^{12}$ & $\tilde{t}_{c}^{13}$ & $\tilde{t}_{c}^{14}$ & $\tilde{t}_{c}^{15}$ & $\tilde{t}_{c}^{16}$ & $\tilde{t}_{c}^{17}$ & $\widetilde{D}_{A 1}=\tilde{t}_{c}^{11} \oplus \tilde{t}_{c}^{12} \oplus \tilde{t}_{c}^{13}$ \\
\hline $\mathrm{A} 2$ & $\tilde{t}_{c}^{21}$ & $\tilde{t}_{c}^{22}$ & $\tilde{t}_{c}^{23}$ & $\tilde{t}_{c}^{24}$ & $\tilde{t}_{c}^{25}$ & $\tilde{t}_{c}^{26}$ & $\tilde{t}_{c}^{27}$ & $\widetilde{D}_{A 2}=\tilde{t}_{c}^{21} \oplus \tilde{t}_{c}^{22} \oplus \tilde{t}_{c}^{23}$ \\
\hline A3 & $\tilde{t}_{c}^{31}$ & $\tilde{t}_{c}^{32}$ & $\tilde{t}_{c}^{33}$ & $\tilde{t}_{c}^{34}$ & $\tilde{t}_{c}^{35}$ & $\tilde{t}_{c}^{36}$ & $\tilde{t}_{c}^{37}$ & $\widetilde{D}_{A 3}=\tilde{t}_{c}^{31} \oplus \tilde{t}_{c}^{32} \oplus \tilde{t}_{c}^{33}$ \\
\hline B1 & $\tilde{t}_{c}^{41}$ & $\tilde{t}_{c}^{42}$ & $\tilde{t}_{c}^{43}$ & $\tilde{t}_{c}^{44}$ & $\tilde{t}_{c}^{45}$ & $\tilde{t}_{c}^{46}$ & $\tilde{t}_{c}^{47}$ & $\widetilde{D}_{B 1}=\tilde{t}_{c}^{44} \oplus \tilde{t}_{c}^{45}$ \\
\hline B2 & $\frac{\tau}{\tilde{t}_{c}^{51}}$ & $\frac{c}{\tilde{t}_{c}^{52}}$ & $\frac{\tau}{\tilde{t}_{c}^{53}}$ & $\frac{\tau}{\tilde{t}_{c}^{54}}$ & $\tilde{t}_{c}^{55}$ & $\frac{\tau}{\tilde{t}_{c}^{56}}$ & $\tilde{t}_{c}^{57}$ & $\widetilde{D}_{B 2}=\tilde{t}_{c}^{54} \oplus \tilde{t}_{c}^{55}$ \\
\hline C1 & $\tilde{t}_{c}^{61}$ & $\tilde{t}_{c}^{62}$ & $\tilde{t}_{c}^{63}$ & $\tilde{t}_{c}^{64}$ & $\tilde{t}_{c}^{65}$ & $\tilde{t}_{c}^{66}$ & $\tilde{t}_{c}^{67}$ & $\widetilde{D}_{C 1}=\tilde{t}_{c}^{66} \oplus \tilde{t}_{c}^{67}$ \\
\hline $\mathrm{C} 2$ & $\tilde{t}_{c}^{71}$ & $\tilde{t}_{c}^{72}$ & $\tilde{t}_{c}^{73}$ & $\tilde{t}_{c}^{74}$ & $\tilde{t}_{c}^{75}$ & $\tilde{t}_{c}^{76}$ & $\tilde{t}_{c}^{77}$ & $\widetilde{D}_{C 2}=\tilde{t}_{c}^{76} \oplus \tilde{t}_{c}^{77}$ \\
\hline$\tilde{R}_{i}$ & 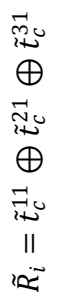 & 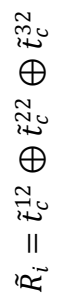 & 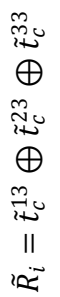 & 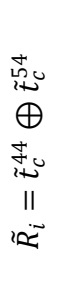 & 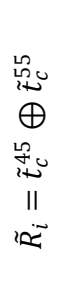 & 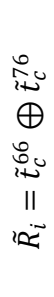 & 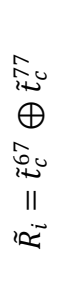 & \\
\hline
\end{tabular}

$$
\begin{aligned}
T_{C} & =H+H^{2}+H^{3}+\ldots+H^{t} \\
& =H\left(I+H+H^{2}+\ldots+H^{t-1}\right)(I-H)(I-H)^{-1} \\
& =H\left(I-H^{t}\right)(I-H)^{-1}=H(I-H)^{-1}, \\
& \text { when } \lim _{t \rightarrow \infty} H^{t} \\
& =[0]_{n \times n} .
\end{aligned}
$$

Where $H=\left[h_{c}^{i j}\right]_{n \times n}, 0 \leq h_{c}^{i j}<1,0<\sum_{j=1}^{n} h_{c}^{i j} \leq 1$, and $0<\sum_{i=1}^{n} h_{c}^{i j} \leq 1$.

Table 2. An example of the total-relation matrix $\widetilde{T_{c}}$ 
For using DEMATEL technique working with fuzzy numbers following steps required:

Step 1: Obtain experts view and calculate the average of all judgments. For $\mathrm{p}$ experts the average $\tilde{z}$ of all expert evaluations calculated by using Eq.4 and each expert assessment forms the initial direct-relation matrix $\tilde{z}^{\mathrm{p}}$ is $\mathrm{n} \times \mathrm{n}$ matrix obtained by pair-wise comparisons in terms of influences and directions between criteria using linguistic variables (five scale ranging) represented as: "no influence," "very low influence," "low influence," "High influence" and "very high influence"; in which $\tilde{z}_{\mathrm{ij}}$ is the triangular fuzzy number and denoted as the degree to which the criterion i affects the criterion j, i.e., $\tilde{z}=\left[\tilde{z}_{\mathrm{ij}}\right]_{\mathrm{n}} \times{ }_{\mathrm{n}}$.

$$
\tilde{z}=\frac{\tilde{z}^{1} \oplus \tilde{z}^{2} \oplus \tilde{z}^{3} \oplus \ldots \oplus \tilde{z}^{p}}{p}
$$

Where

$$
\begin{aligned}
& \tilde{\mathrm{H}}_{\mathrm{ij}}=\left[\begin{array}{ccccc}
\left(l_{11} / r, m_{11} / r, u_{11} / r\right) & \ldots & \left({ }_{1 j} / r, m_{1 j} / r, u_{1 j} / r\right) & \ldots & \left(l_{1 m} / r, m_{1 m} / r, u_{1 m} / r\right) \\
\vdots & & \vdots & & \vdots \\
\left(l_{i 1} / r, m_{i 1} / r, u_{i 1} / r\right) & \ldots & \left(l_{i j} / r, m_{i j} / r, u_{i j} / r\right) & \ldots & \left(l_{i m} / r, m_{i m} / r, u_{i m} / r\right) \\
\vdots & & \vdots & \vdots \\
\left(l_{m i 1} / r, m_{m 1} / r, u_{m 1} / r\right) & \ldots & \left(l_{m j} / r, m_{m j} / r, u_{m j} / r\right) & \ldots & \left(l_{m m} / r, m_{m m} / r, u_{m m} / r\right)
\end{array}\right] \\
& r=\max _{1 \leq i \leq n}\left(\sum_{j=1}^{n} u_{i j}\right) \\
& \tilde{H}_{i j}=\frac{\tilde{z}_{i j}}{r}=\left(\frac{l_{i j}^{\prime}}{r}, \frac{m_{i j}^{\prime}}{r}, \frac{u_{i j}^{\prime}}{r}\right)=\left(l_{i j}^{\prime \prime}, m_{i j}^{\prime \prime}, u_{i j}^{\prime \prime}\right) \\
& \tilde{R}=\left(\tilde{R}_{i}\right)_{1 \times n}=\left[\sum_{j=1}^{n} \tilde{T}_{C}^{i j}\right]_{1 \times n} .
\end{aligned}
$$

Where the sum of each column in direct-relation matrix is close to 1 .

Step 3: The total-relation matrix $\widetilde{\boldsymbol{T}_{\boldsymbol{c}}}$. Total relation matrix $\widetilde{T_{c}}$ can be obtained by using equations (7) to (10), in which $\tilde{T}_{i j}=\left(l_{i j}^{t}, m_{i j}^{t}, u_{i j}^{t}\right)$ and $I$ is an $\mathrm{n} \times \mathrm{n}$ identity matrix.

$$
\begin{gathered}
\tilde{T}_{C}=\tilde{H} \otimes(I \oplus \tilde{H}), \\
T_{C}=\lim _{k \rightarrow+\infty}\left(\tilde{H}^{1} \oplus \tilde{H}^{2} \oplus \ldots \oplus \tilde{H}^{k}\right) \\
{\left[l_{i j}^{\mathrm{t}}\right]=H_{l} \times\left(I-H_{l}\right)^{-1}} \\
{\left[m_{i j}^{\mathrm{t}}\right]=H_{m} \times\left(I-H_{m}\right)^{-1}} \\
{\left[u_{i j}^{\mathrm{t}}\right]=H_{u} \times\left(I-H_{u}\right)^{-1} .}
\end{gathered}
$$

Intensity of all direct and indirect relations of criteria can be gained from Eq. (7).

Step 4: Analyze the results. Within the total-relation matrix $\widetilde{T_{c}}$ through Eq. (11) and (12), $\widetilde{D}$ and $\tilde{R}$ can be obtained as the sum of rows $(\widetilde{D})$ and the sum of columns $(\tilde{R})$ (see Table 2 as an example).

$$
\tilde{D}=\left(\tilde{D}_{i}\right)_{n \times 1}=\left[\sum_{j=1}^{n} \tilde{T}_{c}^{i j}\right]_{n \times 1}
$$

$$
\begin{aligned}
& \tilde{z}_{i j}=\left(l_{i j}, m_{i j}, u_{i j}\right) \\
& =\left[\begin{array}{ccccc}
\left(l_{11}, m_{11}, u_{11}\right) & \ldots & \left(l_{1 j}, m_{1 j}, u_{1 j}\right) & \ldots & \left(l_{1 m}, m_{1 m}, u_{1 m}\right) \\
\vdots & & \vdots & & \vdots \\
\left(l_{i 1}, m_{i 1}, u_{i 1}\right) & \ldots & \left(l_{i j}, m_{i j}, u_{i j}\right) & \ldots & \left(l_{i m}, m_{i m}, u_{i m}\right) \\
\vdots & & \vdots & & \vdots \\
\left(l_{m i 1}, m_{m 1}, u_{m 1}\right) & \ldots & \left(l_{m j}, m_{m j}, u_{m j}\right) & \ldots & \left(l_{m m}, m_{m m}, u_{m m}\right)
\end{array}\right],
\end{aligned}
$$

where $\left(l_{i j}, m_{i j}, u_{i j}\right)$ is triangular fuzzy numbers.

Step 2: Normalizing direct-relation matrix $\tilde{\boldsymbol{z}}$. Normalizing matrix $\tilde{z}$ through using equations (5) and (6), in which makes the normalized direct-relation matrix $\widetilde{H}$, i.e. $\widetilde{H}=\left[\tilde{h}_{i j}\right]_{n \times n}$ and $0 \leq h_{i j} \leq 1$.

Step 5: Finding a causal diagram. Causal diagram can be found by the sum of vector $\widetilde{D}$ and vector $\widetilde{R}$ as the horizontal axis, in which $(\widetilde{D} \oplus \tilde{R})$ named "Prominence" and shows the importance of each criterion related with the others. Same as the horizontal axis, the vertical axis is acquired by subtracting $\widetilde{D}$ from $\widetilde{R}$ and named "Relation" which the positive score of $(\widetilde{D} \ominus \widetilde{R})$, the criterion is arranged to a cause group and if the $(\widetilde{D} \ominus \widetilde{R})$ is negative, it means the criterion is grouped into the effect group.

Step 6: Defuzzify of results to crisp value. In this step values of $\widetilde{D}_{i} \oplus \widetilde{R}_{i}$ and $\widetilde{D}_{i} \ominus \widetilde{R}_{i}$ defuzzify through the below formula.

$$
\mathrm{B}=\frac{\left(\mathrm{a}_{1}+\mathrm{a}_{3}+2 \times \mathrm{a}_{2}\right)}{4},
$$

where $\widetilde{A}=\left(a_{1}, a_{2}, a_{3}\right)$ and $B$ is defuzzify of $\widetilde{A}$.

Based on above steps, two different total influence matrices are then applied. The first one, $\widetilde{T}_{c}=\left[\tilde{t}_{c}^{i j}\right]_{n \times n}$, pertains to n criteria, while the second one, $\widetilde{T_{D}}=\left[\tilde{t}_{D}^{i j}\right]_{n \times n}$, is devoted to $\mathrm{m}$ dimensions (clusters) from $\widetilde{T_{c}}$ (see Table 3 as an example based on Table 3).

Step 7: Calculate the influential weights of DEMATEL combined with ANP. The total influential matrix $\widetilde{T_{c}}$ should be normalized by dividing each elements of matrix $\widetilde{T}_{c}$ to sum of corresponding row (Eq. (13)). 


$$
\begin{aligned}
& c_{11} \\
& c_{12}
\end{aligned}
$$

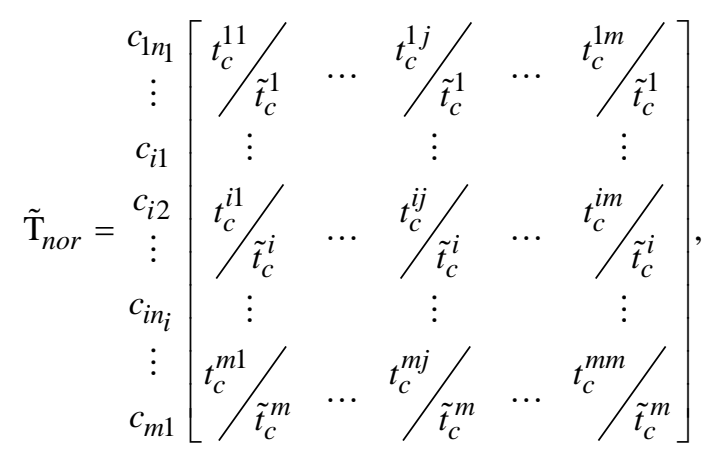

$$
\begin{aligned}
& c_{m 2} \\
& \vdots \\
& \tilde{t}_{c}^{i}=\sum_{j=1}^{m} \tilde{t}_{c}^{i j}
\end{aligned}
$$

Unweighted super-matrix $W$ is calculated by transposing normalized matrix $\widetilde{T}_{c} E q .(14)$, i.e. $\widetilde{W}=$ $\left(\tilde{T}_{c}^{\text {nor }}\right)^{\prime}$.

$$
\begin{aligned}
& c_{11} \\
& c_{12} \\
& \text { ! }
\end{aligned}
$$

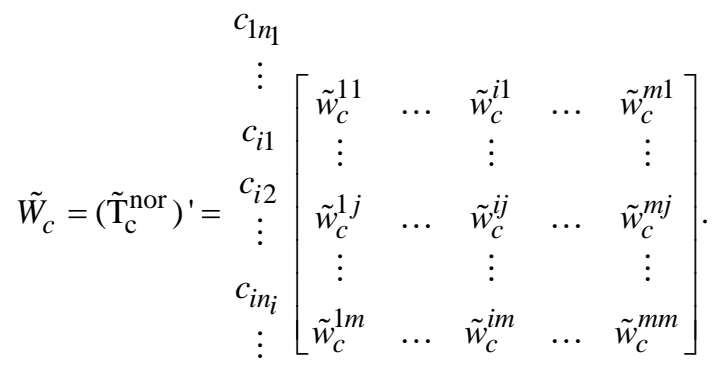

$$
\begin{aligned}
& c_{m 1} \\
& c_{m 2} \\
& \text { : } \\
& c_{m n_{i}}
\end{aligned}
$$

The total-influential matrix $T_{D}$ needs to be normalised by dividing it by the following formula (Eq.15 to Eq.16):

$$
\tilde{t}_{D}^{i}=\sum_{j=1}^{m} \tilde{t}_{D}^{i j} \text { and }
$$

$$
\begin{aligned}
& \tilde{T}_{D}=\left[\begin{array}{ccc}
\tilde{t}_{D}^{11} & \tilde{t}_{D}^{1 j} & \tilde{t}_{D}^{1 m} \\
\tilde{t}_{D}^{i 1} & \tilde{t}_{D}^{i j} & \tilde{t}_{D}^{i m} \\
\tilde{t}_{D}^{m 1} & \tilde{t}_{D}^{m j} & \tilde{t}_{D}^{m m}
\end{array}\right] \rightarrow \sum_{j=1}^{m} \tilde{t}_{D}^{1 j}=\tilde{t}_{D}^{1 j}=\tilde{t}_{D}^{i} \tilde{t}_{D}^{m j}=\tilde{t}_{D}^{m} \\
& \tilde{T}_{D}^{n o r}=\left[\tilde{t}_{D}^{i j} / \tilde{t}_{D}^{i}\right]_{m \times m}
\end{aligned}
$$

Then, each row of the normalized $\tilde{T}_{D}^{\text {nor }}$ can be summed to equal one, so that $\sum_{j=1}^{m} \tilde{t}_{D}^{n o r}{ }_{i j}=1$.

Using ANP model, a weighted super-matrix $\widetilde{W}$, can be obtained based on multiplying matrix $\widetilde{W}$ by normalized total-relation matrix $\tilde{T}_{D}$. And if limit the weighted supermatrix (W') rises to extreme value of $\varphi$, it becomes a stable super-matrix calculated as priority vector, or it determines influential weights for criteria ( $\widetilde{W}_{i}=$ $\left.\lim _{\varphi \rightarrow \infty}\left(\widetilde{W}^{\prime}\right)^{\varphi}\right)$. For finding priority vector instead of using this equation $\left(\widetilde{W}_{i}=\lim _{\varphi \rightarrow \infty}\left(\widetilde{W}^{\prime}\right)^{\varphi}\right)$, eq. 18 can be used, which is easier to apply.

$$
\begin{gathered}
\tilde{W}^{\prime}=\tilde{\mathrm{T}}_{\mathrm{D}}^{\text {nor }} \tilde{W}_{c} \\
=\left[\begin{array}{ccccc}
\tilde{t}_{D}^{n o r_{11}} \times \tilde{W}_{c}^{11} & \ldots & \tilde{t}_{D}^{n o r_{i 1}} \times \tilde{W}_{c}^{i 1} & \ldots & \tilde{t}_{D}^{n o r}{ }_{m 1} \times \tilde{W}_{c}^{m 1} \\
\vdots & & \vdots & & \vdots \\
\tilde{t}_{D}^{n o r_{1 j}} \times \tilde{W}_{c}^{1 j} & \ldots & \tilde{t}_{D}^{n o r_{i j}} \times \tilde{W}_{c}^{i j} & \ldots & \tilde{t}_{D}^{n o r_{m j}} \times \tilde{W}_{c}^{m j} \\
\vdots & & \vdots & & \vdots \\
\tilde{t}_{D}^{n o r_{1 m}} \times \tilde{W}_{c}^{1 m} & \ldots & \tilde{t}_{D}^{n o r_{i m}} \times \tilde{W}_{c}^{i m} & \ldots & \tilde{t}_{D}^{n o r_{m m}} \times \tilde{W}_{c}^{m m}
\end{array}\right] \\
\tilde{W}_{i}=\frac{\sum_{j=1}^{n}\left(\tilde{w}_{i j}^{\prime} / \sum_{i=1}^{n} \tilde{w}_{i j}^{\prime}\right)}{n}, i, j=1,2, \ldots, n .
\end{gathered}
$$

\subsection{The Fuzzy VIKOR Method}

The VIKOR method is a multi-criteria decision making (MCDM) or Multi-criteria decision analysis method. It was originally developed by Opricovic (1998) to solve decision problems with conflicting and noncommensurable (different units) criteria, assuming that compromise is acceptable for conflict resolution, the decision maker wants a solution that is the nearest to the ideal, and the alternatives are evaluated according to all established criteria. VIKOR ranks alternatives and determines the solution named compromise that is the closest to the ideal. The purpose of using VIKOR method for this study is the VIKOR method checks; whether the top-ranked alternative can be considered better enough than the others by testing acceptability advantage and acceptable stability conditions. If any of these two conditions is not satisfied, then VIKOR proposes a set of compromise solutions based on maximum group utility of majority and minimum individual regret of the opponent. Furthermore, another reason for employing the VIKOR method is because this technique is mainly based on the particular measure of closeness to the ideal solution, and it focuses on selecting the best choice from a set of feasible alternatives in presence of mutually conflicting criteria by determining a compromise solution [61].

The steps of the fuzzy VIKOR method are described as follows:

Step 1: Calculating the average of all experts' judgments. For obtaining the average of $\mathrm{k}$ experts $\tilde{b}_{i j}$, Eq.19 is used as same as equation used in step 1 of DEMATEL method. Initial performance matrix $\tilde{b}_{i j}$ is $n \times m$ matrix with the triangular fuzzy numbers and shows as degree to which alternative $m$ initial performance regard to the criterion $\mathrm{n}$. 


$$
\tilde{b}_{i j}=\frac{\tilde{b}^{1} \oplus b^{2} \oplus \tilde{b}^{3} \oplus \ldots \oplus \tilde{b}^{k}}{k},
$$

where

$$
\begin{aligned}
& \tilde{b}_{i j} \\
& =\left[\begin{array}{ccccc}
\left(l_{11}, m_{11}, u_{11}\right) & \ldots & \left(l_{1 j}, m_{1 j}, u_{1 j}\right) & \ldots & \left(l_{1 m}, m_{1 m}, u_{1 m}\right) \\
\vdots & & \vdots & & \vdots \\
\left(l_{i 1}, m_{i 1}, u_{i 1}\right) & \ldots & \left(l_{i j}, m_{i j}, u_{i j}\right) & \ldots & \left(l_{i m}, m_{i m}, u_{i m}\right) \\
\vdots & & \vdots & & \vdots \\
\left(l_{m i 1}, m_{m i 1}, u_{m i 1}\right) & \ldots & \left(l_{m j}, m_{m j}, u_{m j}\right) & \ldots & \left(l_{m m}, m_{m m}, u_{m m}\right)
\end{array}\right] .
\end{aligned}
$$

Step 3. Determine the best $\widetilde{\boldsymbol{p}}_{\boldsymbol{J}}^{*}$ and the worst $\widetilde{\boldsymbol{p}}_{\boldsymbol{J}}^{\wedge}$ values of all criterion performances. By using follow equations:

$\mathrm{i}=1,2, \ldots, \mathrm{n} ; \tilde{p}_{J}^{*}=\max \left(\tilde{b}_{i j}, \mathrm{j}=1, \ldots, \mathrm{J}\right), \tilde{p}_{J}^{\wedge}=\min$ $\left(\tilde{b}_{i j}, \mathrm{j}=1, \ldots, \mathrm{J}\right)$, if the $\mathrm{i}$-th function is benefit;

$\mathrm{i}=1,2, \ldots, \mathrm{n} ; \tilde{p}_{J}^{*}=\min \left(\tilde{b}_{i j}, \mathrm{j}=1, \ldots, \mathrm{J}\right), \tilde{p}_{J}^{\wedge}=\max$ $\left(\tilde{b}_{i j}, \mathrm{j}=1, \ldots, \mathrm{J}\right)$, if the $\mathrm{i}-$ th function is cost $(21)$.

Step 4. Normalizing values of; $\tilde{p}_{J}^{*}=\left(l_{j}^{*}, m_{j}^{*}, u_{j}^{*}\right)$ and $\tilde{p}_{J}^{\wedge}=\left(l_{j}^{\wedge}, m_{j}^{\wedge}, u_{j}^{\wedge}\right)$ through using:

$\widetilde{d_{i j}}=\left(\widetilde{\tilde{p}_{j}^{*}} \ominus \tilde{p}_{i j}\right) /\left(u_{j}^{*} \ominus l_{j}^{\wedge}\right)$, if the i-th function is benefit;

And $\widetilde{d_{i j}}=\left(\tilde{p}_{i j} \ominus \tilde{p}_{J}^{\wedge}\right) /\left(u_{j}^{*} \ominus l_{j}^{\wedge}\right)$, if the i-th function is cost (22).

Step 5. Compute the values $\widetilde{\boldsymbol{S}_{\boldsymbol{i}}}$ and $\widetilde{\boldsymbol{R}_{\boldsymbol{i}}}$. Finding Manhattan distance and Chebyshev distance by the relations:

$$
\tilde{S}_{t}=\sum_{j=1}^{J}\left(\tilde{w}_{i} \otimes \tilde{d}_{i j}\right),
$$

weighted and normalized Manhattan distance;

$$
\tilde{R}_{i}=\max _{j}\left(\tilde{w}_{i} \otimes \tilde{d}_{i j}\right),
$$

weighted and normalized Chebyshev distance;

where $\widetilde{w}_{i}$ are the weights of criteria, expressing the DM's preference as the relative importance of the criteria and it pertained to weighted super-matrix.

Step 6. Find out the final value. Compute the values Qj, $\mathrm{j}=1,2, \ldots, \mathrm{J}$, by the relation:

$$
\widetilde{Q}_{i}=v \frac{\left(\widetilde{S_{t}} \ominus \tilde{s}^{*}\right)}{\left(\tilde{S}_{u}^{\wedge} \ominus \tilde{S}_{l}^{*}\right)} \oplus(1-v) \frac{\left(\tilde{R}_{i} \ominus \tilde{R}^{*}\right)}{\left(\tilde{R}_{u}^{\wedge} \ominus \tilde{R}_{l}^{*}\right)},
$$

Where $\tilde{S}^{*}=\min _{i} \tilde{S}_{i}, \widetilde{S}_{i}^{*}=\min _{i}^{l} \tilde{S}_{i}^{l}, \tilde{S}_{u}^{\wedge}=\max _{i}^{u} \tilde{S}_{i}^{u}$, $\tilde{R}^{*}=\min _{i} \tilde{R}_{i}, \tilde{R}_{u}^{\wedge}=\max _{i}^{u} \tilde{R}_{i}^{u},{\widetilde{R_{i}}}^{*}=\min _{i}^{l} \tilde{R}_{i}^{l} ;$ and is introduced as a weight for the strategy of maximum group utility, whereas $1-\mathrm{v}$ is the weight of the individual regret. These strategies could be compromised by $\mathrm{v}=0.5$, and here $\mathrm{v}$ is modified as $=(\mathrm{n}+1) / 2 \mathrm{n}($ from $\mathrm{v}+0.5(\mathrm{n}-1) / \mathrm{n}=1)$ since the criterion ( 1 of $n$ ) related to $R$ is included in $S$, too.

Step 7. Defuzzify values of $\widetilde{\boldsymbol{S}}, \widetilde{\boldsymbol{R}}$ and $\widetilde{\boldsymbol{Q}}$. Defuzzyify values by using following formula:

$$
\begin{aligned}
& \operatorname{Crisp}(\tilde{S})=\frac{2 m+l+u}{4}, \\
& \operatorname{Crisp}(\tilde{R})=\frac{2 m+l+u}{4}, \\
& \operatorname{Crisp}(\tilde{Q})=\frac{2 m+l+u}{4} .
\end{aligned}
$$

Step 8. Rank the alternatives. Sorting by the values $\mathrm{S}^{\text {def }}, \mathrm{R}^{\text {def }}$ and $\mathrm{Q}^{\text {def }}$, from the minimum value. The results are three ranking lists.

Step 9. Propose as a compromise solution the alternative $\mathrm{A}(1)$ which is the best ranked by the measure $\mathrm{Q}$ (minimum) if the following two conditions are satisfied:

C1. "Acceptable Advantage": $\mathrm{Q}(\mathrm{A}(2))-\mathrm{Q}(\mathrm{A}(1))>=$ DQ where: $A(2)$ is the alternative with second position in the ranking list by $\mathrm{Q} ; \mathrm{DQ}=1 /(\mathrm{J}-1)$.

C2. "Acceptable Stability in decision making": The alternative A (1) must also be the best ranked by S or/and R.

This compromise solution is stable within a decisionmaking process, which could be the strategy of maximum group utility (when $\mathrm{v}>0.5$ is needed), or "by consensus" $\mathrm{v}$ about 0.5 , or "with veto" $\mathrm{v}<0.5$ ). If one of the conditions is not satisfied, then a set of compromise solutions is proposed, which consists of: - Alternatives $A(1)$ and $A(2)$ if only the condition $C 2$ is not satisfied, or Alternatives $A(1), A(2), \ldots, A(M)$ if the condition $C 1$ is not satisfied; $A(M)$ is determined by the relation $Q(A(M))-$ $\mathrm{Q}(\mathrm{A}(1))<\mathrm{DQ}$ for maximum $\mathrm{M}$ (the positions of these alternatives are "in closeness").

\section{Empirical Study}

\subsection{SADR Elevated Expressway in Tehran, Iran}

The Study area is located in southern of region 1 in Tehran city. Heavy personal vehicle's traffic from the east of Tehran imposes high pressure on transportation. Network of this city and old Sadr expressway does not meet this need. Therefore, two alternatives proposed to tackle this issue. First alternative is a new urban expressway parallel to Sadr expressway (shown in Figure 2) and second alternative is upgrading Sadr expressway to an elevated expressway (shown in Figure 3). Sadr elevated Expressway is a freeway in northern Tehran, Iran. This freeway runs west from the Modarres Expressway in Gholhak neighborhood east through Gheytarieh, Doulat, Darrous, Chizar, and Ekhtiariyeh, at which point it crosses Pasdaran Avenue and becomes Babayi Expressway. Sadr Expressway serves the dual purpose of connecting the northeastern suburbs of Tehran to the business center, as well as functioning as an arterial road between the capital and the north and northeast of Iran. This bridge consists of the main bridge with $22.7 \mathrm{~m}$ width and $6 \mathrm{~km}$ length and over than three set rams with $5 \mathrm{~km}$ length at all.

\subsection{Materials}

Based on criteria were described in literature review (Table 1) this study was executed according to three steps as follows:

Step1: The fuzzy DEMATEL method to build network relations map. According to DEMATEL method, five experts, including urban managers, urban planners and environmentalists (see Appendix A, table A1) were invited to discuss the relationship and level of criteria and to score the relationship between criteria. For 
evaluating relationship based on fuzzy DEMATEL

relationships between criteria and each linguistic variables approach, respondents used lingual variables to judge

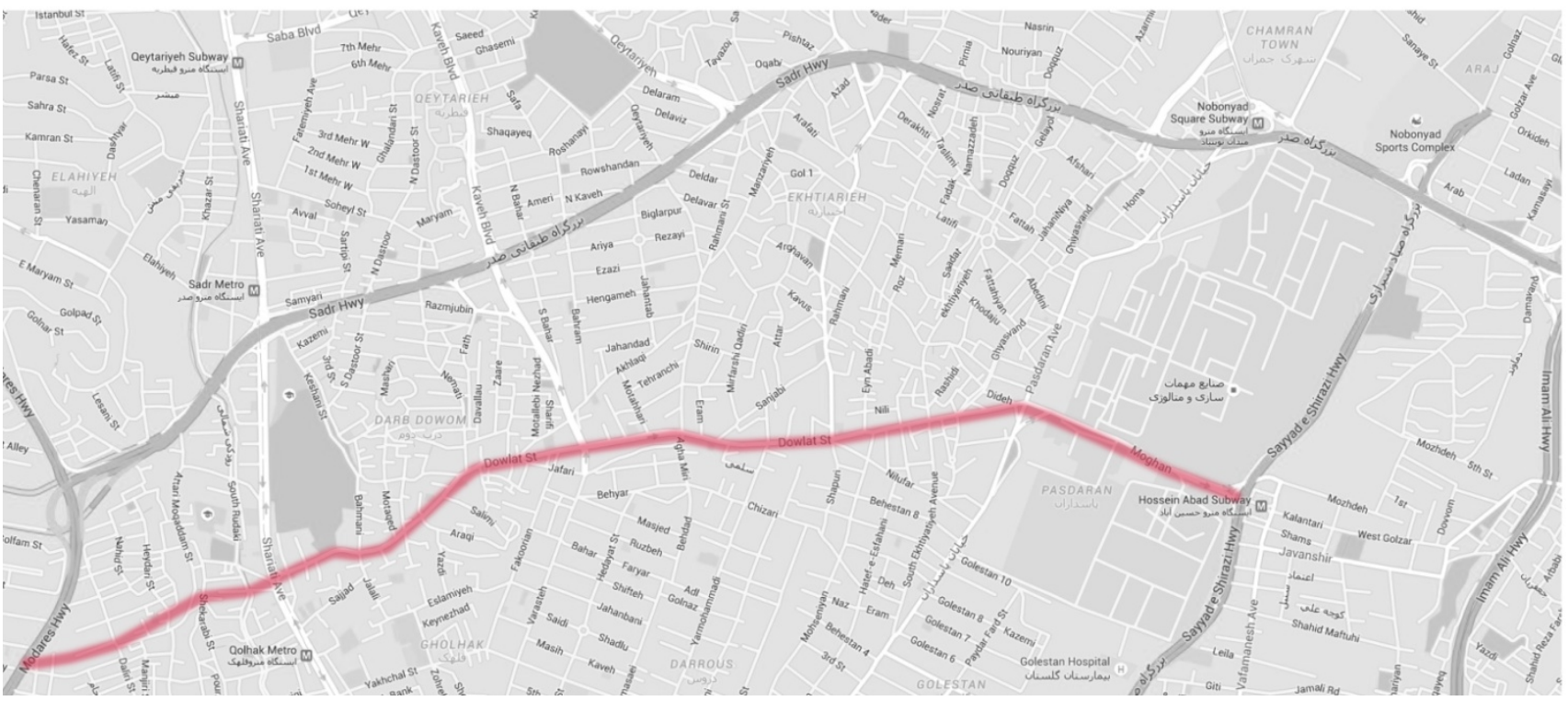

Figure 2. Sit of Alternative 1

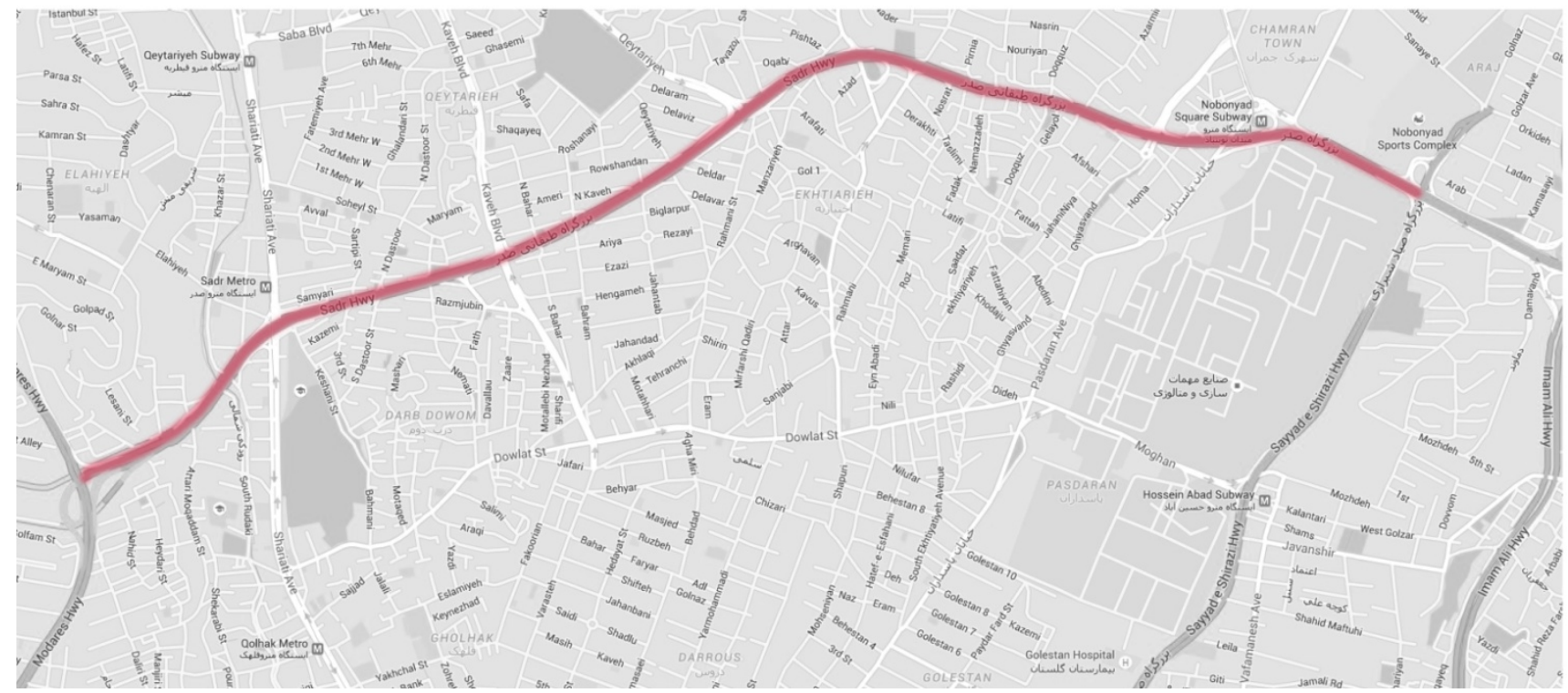

Figure 3. Sit of Alternative 2

Table 3. An example of the total-relation matrix $\widetilde{T_{D}}$

\begin{tabular}{|c|c|c|c|}
\hline Dimension & $\mathrm{A}$ & $\mathrm{B}$ & $\mathrm{C}$ \\
\hline $\mathrm{A}$ & $\tilde{t}_{D}^{11}=\left(\begin{array}{l}\tilde{t}_{c}^{11} \oplus \tilde{t}_{c}^{12} \oplus \tilde{t}_{c}^{13} \oplus \tilde{t}_{c}^{21} \oplus \tilde{t}_{c}^{22} \\
\oplus \tilde{t}_{c}^{23} \oplus \tilde{t}_{c}^{31} \oplus \tilde{t}_{c}^{32} \oplus \tilde{t}_{c}^{33}\end{array}\right) \div 9$ & $\tilde{t}_{D}^{12}=\left(\begin{array}{l}\tilde{t}_{c}^{14} \oplus \tilde{t}_{c}^{15} \oplus \tilde{t}_{c}^{24} \\
\tilde{t}_{c}^{25} \oplus \tilde{t}_{c}^{34} \oplus \tilde{t}_{c}^{35}\end{array}\right) \div 6$ & $\tilde{t}_{D}^{13}=\left(\begin{array}{l}\tilde{t}_{c}^{16} \oplus \tilde{t}_{c}^{17} \oplus \tilde{t}_{c}^{26} \\
\oplus \tilde{t}_{c}^{27} \oplus \tilde{t}_{c}^{36} \oplus \tilde{t}_{c}^{37}\end{array}\right) \div 6$ \\
\hline $\mathrm{B}$ & $\tilde{t}_{D}^{21}=\left(\begin{array}{l}\tilde{t}_{c}^{37} \oplus \tilde{t}_{c}^{42} \oplus \tilde{t}_{c}^{43} \\
\tilde{t}_{c}^{51} \oplus \tilde{t}_{c}^{52} \oplus \tilde{t}_{c}^{53}\end{array}\right) \div 6$ & $\tilde{t}_{D}^{22}=\left(\begin{array}{l}\tilde{t}_{c}^{44} \oplus \tilde{t}_{c}^{45} \\
\oplus \tilde{t}_{c}^{54} \oplus \tilde{t}_{c}^{55}\end{array}\right) \div 4$ & $\tilde{t}_{D}^{23}=\left(\begin{array}{l}\tilde{t}_{c}^{46} \oplus \tilde{t}_{c}^{47} \\
\oplus \tilde{t}_{c}^{56} \oplus \tilde{t}_{c}^{57}\end{array}\right) \div 4$ \\
\hline $\mathrm{C}$ & $\tilde{t}_{D}^{31}=\left(\begin{array}{l}\tilde{t}_{c}^{61} \oplus \tilde{t}_{c}^{62} \oplus \tilde{t}_{c}^{63} \\
\oplus \tilde{t}_{c}^{71} \oplus \tilde{t}_{c}^{72} \oplus \tilde{t}_{c}^{73}\end{array}\right) \div 6$ & $\tilde{t}_{D}^{32}=\left(\begin{array}{l}\tilde{t}_{c}^{64} \oplus \tilde{t}_{c}^{65} \\
\oplus \tilde{t}_{c}^{74} \oplus \tilde{t}_{c}^{75}\end{array}\right) \div 4$ & $\tilde{t}_{D}^{33}=\left(\begin{array}{l}\tilde{t}_{c}^{66} \oplus \tilde{t}_{c}^{67} \\
\tilde{t}_{c}^{76} \oplus \tilde{t}_{c}^{77}\end{array}\right) \div 4$ \\
\hline
\end{tabular}


Table 4. Values of each linguistic variables

\begin{tabular}{|c|c|}
\hline Linguistic variables & Value \\
\hline No influence & $(0,0,0.2)$ \\
\hline Very low influence & $(0,0.2,0.4)$ \\
\hline Low influence & $(0.2,0.4,0.6)$ \\
\hline High influence & $(0.4,0.6,0.8)$ \\
\hline Very high influence & $(0.6,0.8,1)$ \\
\hline
\end{tabular}

Step 2: Combining fuzzy DEMATEL with ANP (DANP) to obtain the weights of criteria. Based on fuzzy DEMATEL results, Total-influential criteria matrix and Total-influential dimensions were found and ANP technique employed to calculate weighted super-matrix and final criteria weights.

Table 5. Values of each linguistic variables

\begin{tabular}{|c|c|}
\hline Linguistic variables & Value \\
\hline Very poor performance & $(0,0,1)$ \\
\hline Poor performance & $(0,1,3)$ \\
\hline Little poor performance & $(1,3,5)$ \\
\hline Middle performance & $(3,5,7)$ \\
\hline Little strong performance & $(5,7,9)$ \\
\hline
\end{tabular}

Step 3: The fuzzy VIKOR method to find out the best alternative. Questionnaire 2 was designed to investigate alternative performance regarding to each criterion. Questionnaire 2, an email questionnaire, asked 10 experts (see Appendix B) to score the performance value of criteria of alternatives based on linguistic variables (shown in Table 5). Respondents included experts and professionals in urban planning and environment fields. The scores are based on triangular fuzzy numbers pertain to linguistic variables as shown in Table 3. Then based on respondents' judgment fuzzy VIKOR applied to index alternatives from the best to the worst.

\section{Results}

This study approach has three results based on three stages described in materials' section and contains the following discussion:

Results of step1:

The experts' judgments gathered and average of all assessments calculated (see average of all experts in Appendix A) then the total-influential matrix and network relations map shown in Table 6 and Figure 4. Based on network relations map, influence of 5 dimensions and 17 criteria on each other can be understood. Results from Figure 4 and Table 6, firstly, show impacts of each dimension and criteria on others and secondly illustrate which criteria or dimension is dependent/independent variable. Among all criteria, those have positive values of (D-R) for example "(a3) Safety and Security" with the highest score, intensely affected others, and it grouped into the independent factors. Criteria with the negative score of (D-R) i.e. "(a4) Restricted access problems” with lowest mark, effected by other criteria, and it plays a role as a dependent factor. The more value of $(D+R)$ for criterion means that criterion has a stronger role in the cause/effect group, as an illustration "Land acquisition (b3)" has more effect on other criteria than "(b2) Traffic Management” for constructing an urban expressway in urban environment.

For dimension "A Social environment," based on Table 6 and Figure 4 (a3) Safety and Security criterion has the highest (D-R) score as 0.138, which makes this criterion affected other criteria (a1, a2 and a4), act as an independence criterion, and grouped in the cause group. In addition "(a3) Safety and Security" criterion has the highest influential impact (D) score as 0.504, and it is the lowest influence impact (R) as 0.366 , so it is the most important criterion in this dimension. The next criterion grouped in the cause group is "(a2) Relocation of houses" criterion, which has second high influential impact (D) score (0.44). Two remained criteria "(a1) Social justice" and "(a4) Restricted access problems" are placed, in the effect group based on their negative values of D-R as -0.027 and -0.124 , so these two criteria are dependence and affected by two cause criteria.

According to Table 6 and Figure 4 "B Spatial environment" dimension had two criteria as "Land acquisition (b3)" and "Traffic management (b2)" are grouped in cause factor with (D-R) score as 0.057 and 0.052 respectively. On the other hand, one remained criterion "(b1) Public utilities" grouped as effect one and act as a dependent criterion.

In "C Visual environment" dimension, one criterion grouped in the cause factors is "(c2) Landscape and visual appearance" with (D-R) score as 0.001, based on influential impacts (D) and influence impacts (R) which are (0.198) and (0.197) respectively. "(c1) Aesthetic and Architectural value" criterion is grouped in the effect factors based on a negative score of D-R as -0.001.

The next dimension "D Economic environment" has two cause criteria and two effect criteria. The two independence criteria are "(d2) Land and real estate prices" and "(d4) Time saving” which has a positive score of D-R as 0.111 and 0.067 . Based on their values of $\mathrm{D}+\mathrm{R}$ score as 0.866 and 0.864 , "d2" and "d4" criteria has a strong role in the cause group of their dimension. The two criteria in the effect group are "(d1) Income residents and shopkeepers" and "(d3) the investment within the region" based on their negative score of (D-R) as -0.108 and -0.07 .

In the last dimension "E Physical and chemical environment," the tallest positive score of (D-R) is 0.189 and that is belonged to "Air pollution (e1)," and this criterion has the highest score of influential impact (0.518) and low score of influence impact (0.33), which is one of the highest ranks within the cause group. Next criterion in cause factors is "(e3) Noise pollution" with the positive score of (D-R) as 0.006 and its influential impact score and influence impact are 0.428 and 0.422 . Two criteria "(e2) Water pollution” and "(e4) Environmental damage" are placed in the effect group based on their negative (DR) scores (-0.14 and -0.054) and in dimension "E Physical and chemical environment" these two criteria are dependence criteria.

The next dimension "D Economic environment" has two cause criteria and two effect criteria. The two independence criteria are "(d2) Land and real estate prices" and "(d4) Time saving” which has a positive score of D-R 
as 0.111 and 0.067 . Based on their values of $\mathrm{D}+\mathrm{R}$ score as 0.866 and 0.864 , “d2" and "d4" criteria has a strong role in the cause group of their dimension. The two criteria in the effect group are "(d1) Income residents and shopkeepers" and "(d3) the investment within the region" based on their negative score of (D-R) as -0.108 and -0.07 .

Table 6. Sum of influences given and received on dimensions and criteria.

\begin{tabular}{|c|c|c|c|c|c|c|c|c|}
\hline criteria & $\widetilde{D}$ & $\widetilde{\boldsymbol{R}}$ & $\widetilde{\boldsymbol{D}}+\widetilde{\boldsymbol{R}}$ & $\widetilde{\boldsymbol{D}}-\widetilde{\boldsymbol{R}}$ & $\mathrm{D}$ & $\mathrm{R}$ & $\mathrm{D}+\mathrm{R}$ & D-R \\
\hline $\begin{array}{c}\text { A. Social } \\
\text { environment }\end{array}$ & $(1.846,5.167,17.19)$ & $(2.376,5.987,19.057)$ & $(4.222,11.154,36.246)$ & $(-0.531,-0.82,-1.867)$ & 7.342 & 8.352 & 15.694 & -1.009 \\
\hline $\begin{array}{c}\text { (a1) Social } \\
\text { justice }\end{array}$ & $(0.093,0.285,1.009)$ & $(0.119,0.312,1.039)$ & $(0.212,0.597,2.048)$ & $(-0.026,-0.027,-0.03)$ & 0.418 & 0.446 & 0.864 & -0.027 \\
\hline $\begin{array}{c}\text { (a2) Relocation } \\
\text { of houses }\end{array}$ & $(0.112,0.306,1.036)$ & $(0.102,0.294,1.016)$ & $(0.214,0.599,2.052)$ & $(0.01,0.012,0.02)$ & 0.44 & 0.426 & 0.866 & 0.014 \\
\hline $\begin{array}{l}\text { (a3) Safety and } \\
\text { Security }\end{array}$ & $(0.151,0.36,1.146)$ & $(0.065,0.243,0.915)$ & $(0.216,0.603,2.06)$ & $(0.086,0.117,0.231)$ & 0.504 & 0.366 & 0.871 & 0.138 \\
\hline $\begin{array}{c}\text { (a4) Restricted } \\
\text { access problems }\end{array}$ & $(0.071,0.247,0.912)$ & $(0.141,0.349,1.133)$ & $(0.212,0.596,2.045)$ & $(-0.07,-0.102,-0.221)$ & 0.369 & 0.493 & 0.862 & -0.124 \\
\hline $\begin{array}{c}\text { B. Spatial } \\
\text { environment }\end{array}$ & $(1.6,4.209,13.651)$ & $(1.574,4.168,13.558)$ & $(3.174,8.376,27.209)$ & $(0.027,0.041,0.094)$ & 5.917 & 5.867 & 11.784 & 0.051 \\
\hline $\begin{array}{l}\text { (b1) Public } \\
\text { utilities }\end{array}$ & $(0.05,0.174,0.654)$ & $(0.101,0.26,0.867)$ & $(0.151,0.434,1.52)$ & $(-0.051,-0.087,-0.213)$ & 0.263 & 0.372 & 0.635 & -0.109 \\
\hline $\begin{array}{l}\text { (b2) Traffic } \\
\text { Management }\end{array}$ & $(0.089,0.238,0.808)$ & $(0.062,0.196,0.711)$ & $(0.15,0.434,1.519)$ & $(0.027,0.042,0.098)$ & 0.343 & 0.291 & 0.634 & 0.052 \\
\hline $\begin{array}{l}\text { (b3) Land } \\
\text { acquisition }\end{array}$ & $(0.088,0.239,0.818)$ & $(0.064,0.195,0.703)$ & $(0.152,0.435,1.521)$ & $(0.024,0.044,0.115)$ & 0.346 & 0.289 & 0.636 & 0.057 \\
\hline $\begin{array}{c}\text { C. Visual } \\
\text { environment }\end{array}$ & $(1.213,3.031,9.615)$ & $(0.885,2.526,8.463)$ & $(2.098,5.557,18.079)$ & $(0.327,0.506,1.152)$ & 4.223 & 3.6 & 7.823 & 0.623 \\
\hline $\begin{array}{c}\text { (c1) Aesthetic } \\
\text { and architectural } \\
\text { values }\end{array}$ & $(0.04,0.129,0.485)$ & $(0.042,0.131,0.483)$ & $(0.082,0.26,0.968)$ & $(-0.002,-0.001,0.002)$ & 0.196 & 0.197 & 0.393 & -0.001 \\
\hline $\begin{array}{c}\text { (c2) Landscape } \\
\text { and visual } \\
\text { appearance }\end{array}$ & $(0.043,0.131,0.484)$ & $(0.04,0.13,0.486)$ & $(0.083,0.261,0.971)$ & $(0.002,0.001,-0.002)$ & 0.198 & 0.197 & 0.395 & 0.001 \\
\hline $\begin{array}{l}\text { D. Economic } \\
\text { environment }\end{array}$ & $(1.57,4.741,16.219)$ & $(2.666,6.434,20.075)$ & $(4.236,11.175,36.295)$ & $(-1.096,-1.693,-3.856)$ & 6.818 & 8.903 & 15.72 & -2.085 \\
\hline $\begin{array}{c}\text { (d1) Income } \\
\text { residents and } \\
\text { shopkeepers } \\
\end{array}$ & $(0.075,0.25,0.914)$ & $(0.132,0.338,1.113)$ & $(0.206,0.588,2.027)$ & $(-0.057,-0.088,-0.199)$ & 0.372 & 0.48 & 0.852 & -0.108 \\
\hline $\begin{array}{l}\text { (d2) Land and } \\
\text { real estate prices }\end{array}$ & $(0.14,0.346,1.122)$ & $(0.074,0.253,0.931)$ & $(0.213,0.599,2.053)$ & $(0.066,0.093,0.191)$ & 0.488 & 0.378 & 0.866 & 0.111 \\
\hline $\begin{array}{c}\text { (d3) The } \\
\text { investment in } \\
\text { the region }\end{array}$ & $(0.083,0.267,0.959)$ & $(0.125,0.326,1.079)$ & $(0.209,0.592,2.037)$ & $(-0.042,-0.059,-0.12)$ & 0.394 & 0.464 & 0.858 & -0.07 \\
\hline $\begin{array}{c}\text { (d4) Time } \\
\text { saving }\end{array}$ & $(0.123,0.326,1.088)$ & $(0.09,0.272,0.961)$ & $(0.212,0.598,2.049)$ & $(0.033,0.054,0.128)$ & 0.466 & 0.399 & 0.864 & 0.067 \\
\hline $\begin{array}{l}\text { E. Physical and } \\
\text { chemical } \\
\text { environment }\end{array}$ & $(2.748,6.561,20.365)$ & $(1.476,4.595,15.887)$ & $(4.224,11.157,36.253)$ & $(1.273,1.966,4.478)$ & 9.059 & 6.638 & 15.698 & 2.421 \\
\hline $\begin{array}{c}\left(\mathrm{e}_{1}\right) \text { Air } \\
\text { pollution } \\
\end{array}$ & $(0.164,0.374,1.162)$ & $(0.04,0.211,0.858)$ & $(0.204,0.585,2.02)$ & $(0.125,0.163,0.304)$ & 0.518 & 0.33 & 0.848 & 0.189 \\
\hline $\begin{array}{l}\left(\mathrm{e}_{2}\right) \text { Water } \\
\text { pollution }\end{array}$ & $(0.062,0.238,0.904)$ & $(0.149,0.357,1.14)$ & $(0.211,0.595,2.044)$ & $(-0.087,-0.119,-0.236)$ & 0.361 & 0.501 & 0.861 & -0.14 \\
\hline $\begin{array}{l}\left(\mathrm{e}_{3}\right) \text { Noise } \\
\text { pollution }\end{array}$ & $(0.104,0.296,1.017)$ & $(0.1,0.291,1.008)$ & $(0.204,0.586,2.025)$ & $(0.004,0.005,0.009)$ & 0.428 & 0.422 & 0.85 & 0.006 \\
\hline $\begin{array}{c}\left(\mathrm{e}_{4}\right) \\
\text { Environmental } \\
\text { damage } \\
\end{array}$ & $(0.082,0.27,0.976)$ & $(0.124,0.319,1.053)$ & $(0.206,0.589,2.029)$ & $(-0.042,-0.049,-0.077)$ & 0.4 & 0.454 & 0.853 & -0.054 \\
\hline
\end{tabular}

Table 7. Total-influential criteria matrix $\widetilde{T}_{D}$.

\begin{tabular}{|c|c|c|c|c|c|c|c|}
\hline \multicolumn{2}{|c|}{ Dimensions } & A & B & C & D & E & $\widetilde{D}$ \\
\hline $\begin{array}{c}\text { Social } \\
\text { environment }\end{array}$ & A & $(0.427,1.198,4.103)$ & $(0.427,1.198,4.103)$ & $(0.182,0.559,1.904)$ & $(0.588,1.45,4.538)$ & $(0.323,1.039,3.597)$ & $(1.846,5.167,17.19)$ \\
\hline $\begin{array}{c}\text { Spatial } \\
\text { environment }\end{array}$ & $\mathrm{B}$ & $(0.452,1.101,3.424)$ & $(0.452,1.101,3.424)$ & $(0.175,0.47,1.526)$ & $(0.485,1.163,3.588)$ & $(0.262,0.824,2.834)$ & $(1.6,4.209,13.651)$ \\
\hline $\begin{array}{c}\text { Visual } \\
\text { environment }\end{array}$ & $\mathrm{C}$ & $(0.334,0.786,2.406)$ & $(0.334,0.786,2.406)$ & $(0.083,0.261,0.97)$ & $(0.386,0.857,2.547)$ & $(0.198,0.59,1.991)$ & $(1.213,3.031,9.615)$ \\
\hline $\begin{array}{c}\text { Economic } \\
\text { environment }\end{array}$ & $\mathrm{D}$ & $(0.439,1.229,4.055)$ & $(0.439,1.229,4.055)$ & $(0.137,0.497,1.782)$ & $(0.42,1.189,4.083)$ & $(0.28,0.964,3.406)$ & $(1.57,4.741,16.219)$ \\
\hline $\begin{array}{c}\text { Physical and } \\
\text { chemical } \\
\text { environment }\end{array}$ & $\mathrm{E}$ & $(0.725,1.673,5.069)$ & $(0.725,1.673,5.069)$ & $(0.309,0.739,2.282)$ & $(0.786,1.775,5.32)$ & $(0.413,1.177,4.059)$ & $(2.748,6.561,20.365)$ \\
\hline & $\widetilde{R}$ & $(2.376,5.987,19.057)$ & $(1.574,4.168,13.558)$ & $(0.885,2.526,8.463)$ & $(2.666,6.434,20.075)$ & $(1.476,4.595,15.887)$ & \\
\hline
\end{tabular}




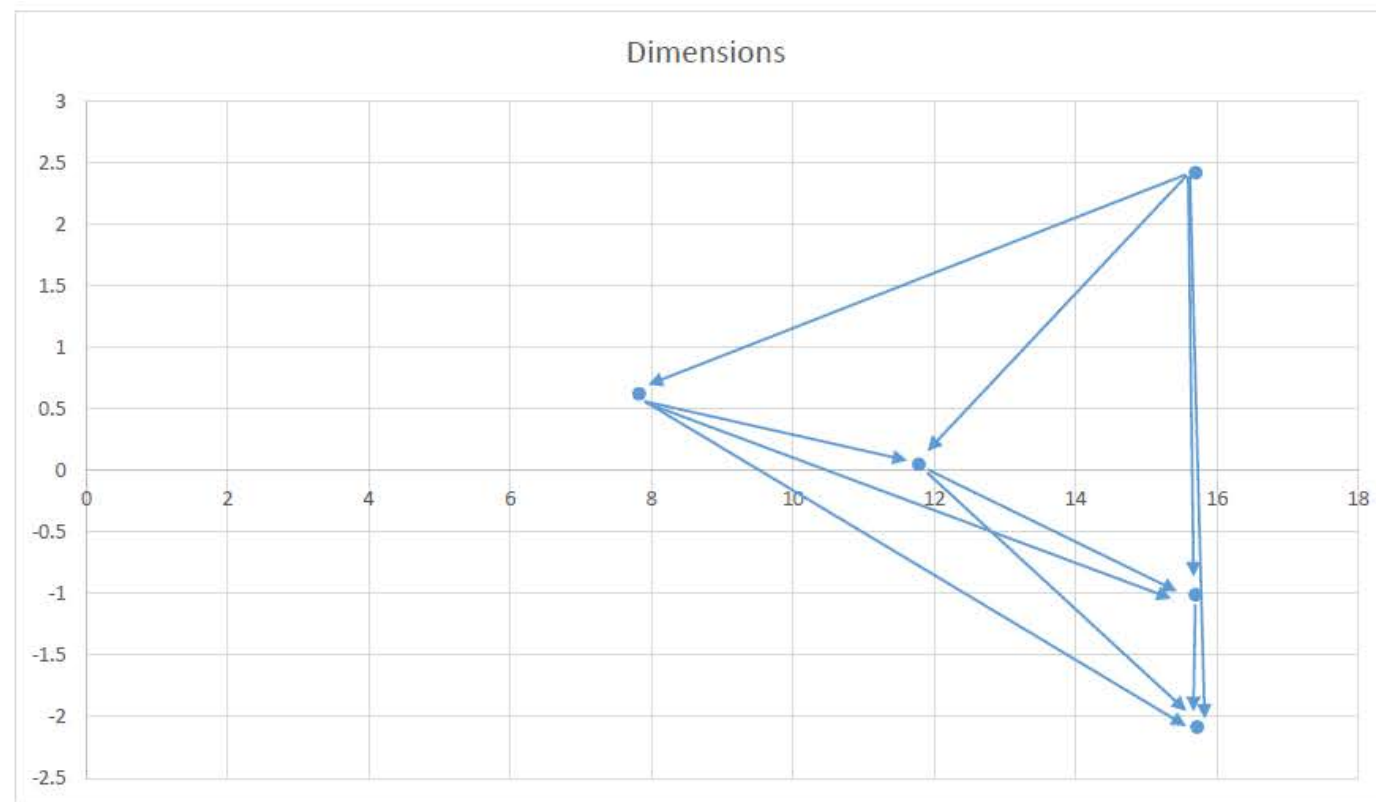

A. Social environment

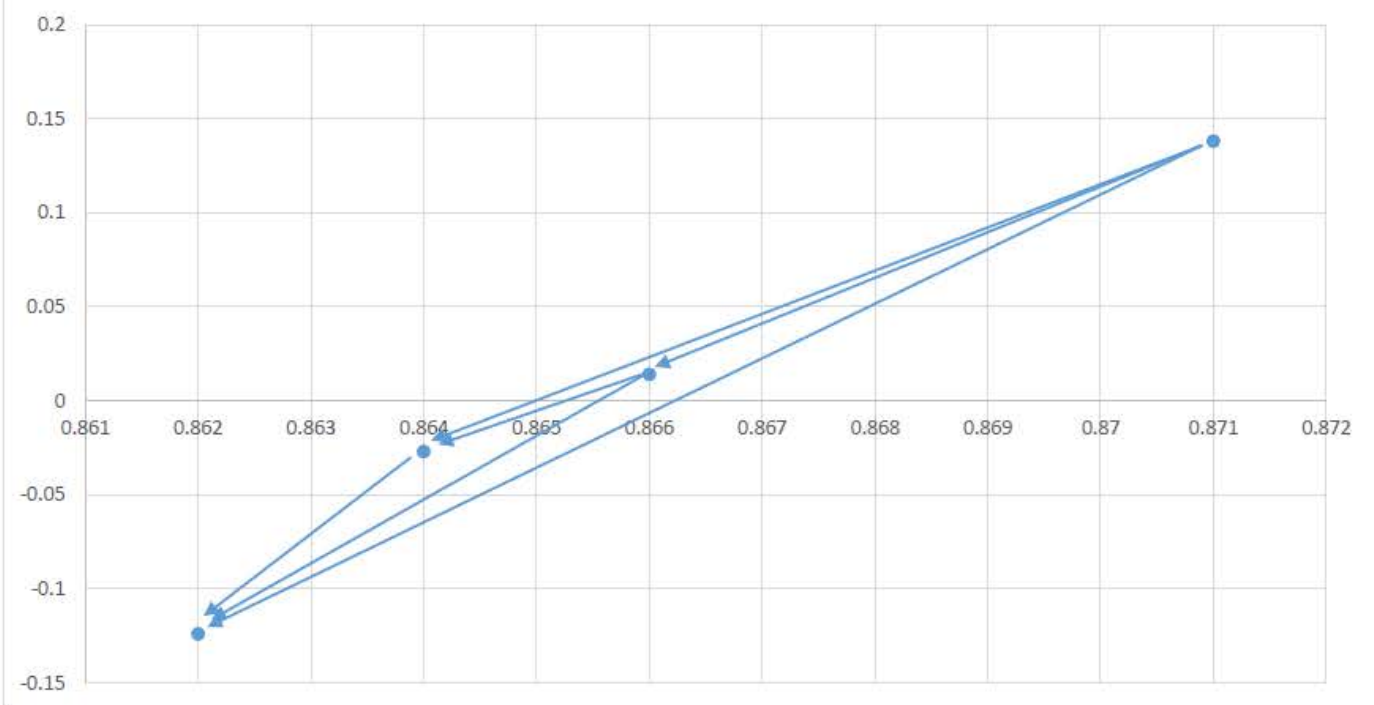

B. Spatial environment

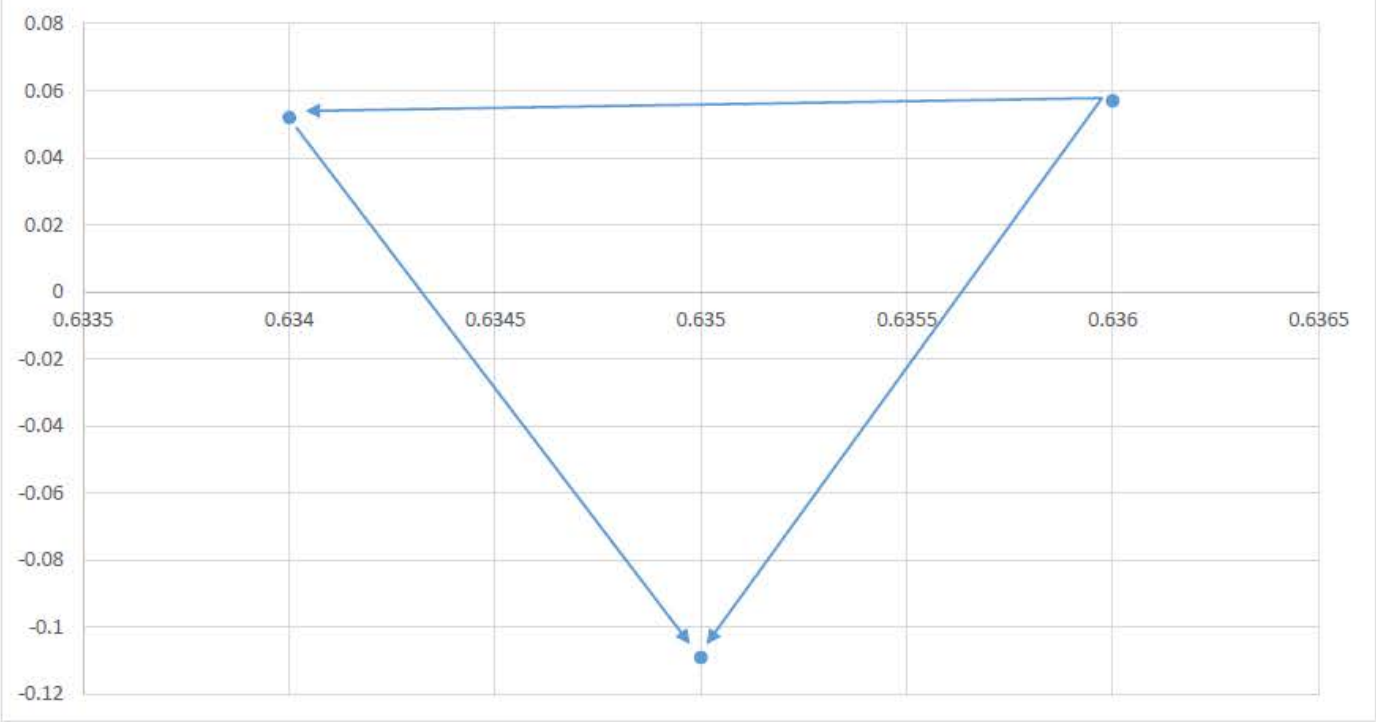

Figure 4. 


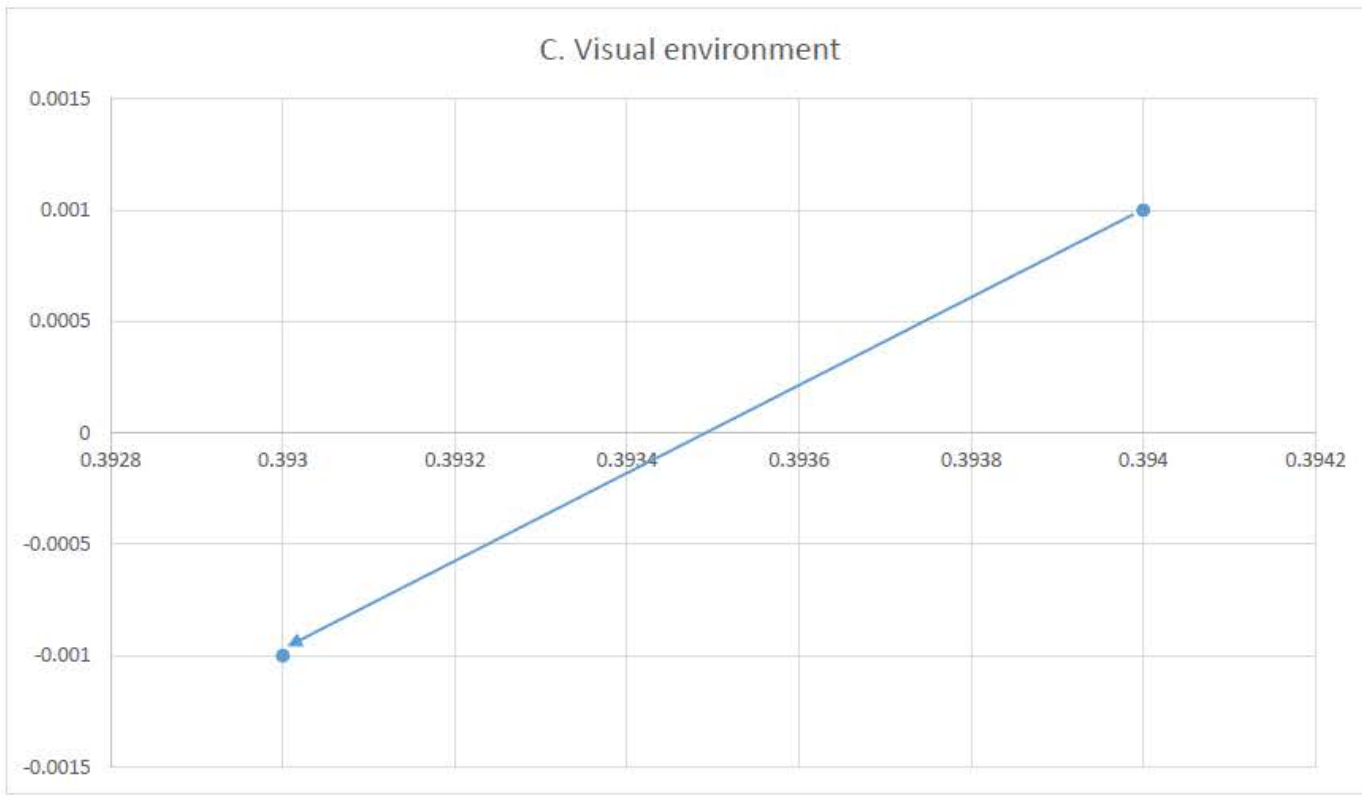

D. Economic environment

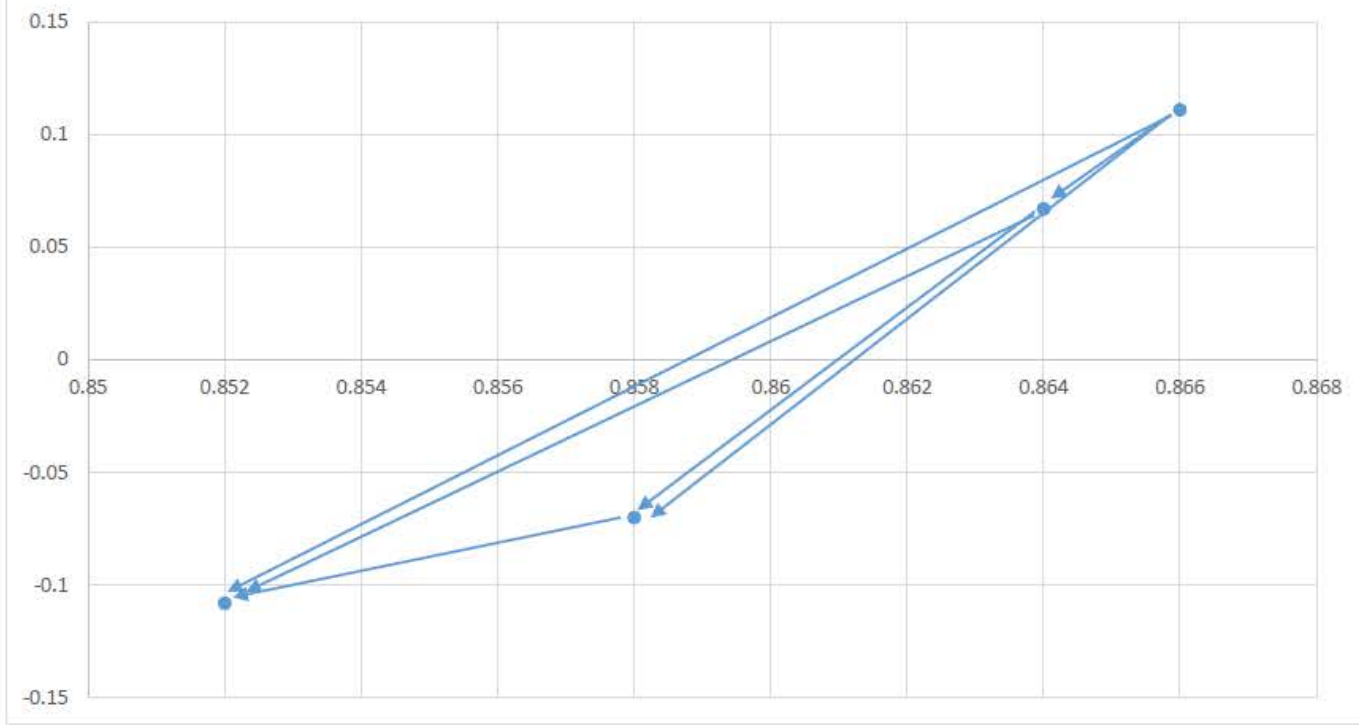

E. Physical and chemical environment

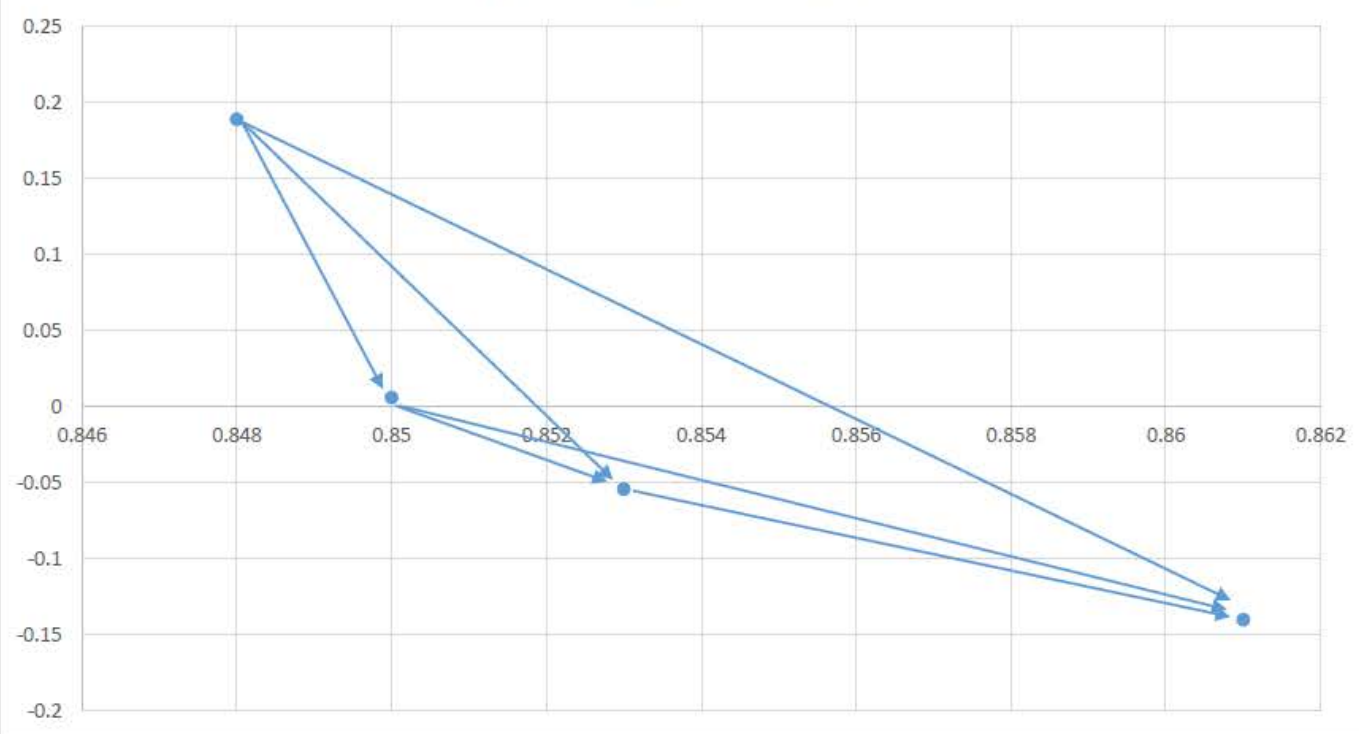

Figure 4. Network relationship map 
In the last dimension "E Physical and chemical environment," the tallest positive score of (D-R) is 0.189 and that is belonged to "Air pollution (e1)," and this criterion has the highest score of influential impact (0.518) and low score of influence impact (0.33), which is one of the highest ranks within the cause group. Next criterion in cause factors is “(e3) Noise pollution” with the positive score of (D-R) as 0.006 and its influential impact score and influence impact are 0.428 and 0.422 . Two criteria “(e2) Water pollution” and “(e4) Environmental damage” are placed in the effect group based on their negative (D-R) scores (-0.14 and -0.054) and in dimension " $E$ Physical and chemical environment" these two criteria are dependence criteria.

Results of stage 2:

The weights of 17 criteria were obtained by combining DEMATEL method with ANP technique for using in next step to evaluating alternatives. The criteria weights were shown in Table 8.

Table 8. Finding the weights of criteria based on Eq.18.

\begin{tabular}{|c|c|c|c|}
\hline Criteria & $\sum_{j=1}^{n}\left(\tilde{w}_{i j}^{\prime} / \sum_{i=1}^{n} \tilde{w}_{i j}^{\prime}\right)$ & $\widetilde{W}_{i}$ & $W_{i}^{d e f}$ \\
\hline a1 & $(1.122,1.073,1.053)$ & $(0.066,0.063,0.062)$ & 0.0635 \\
\hline a2 & $(1.112,1.062,1.044)$ & $(0.065,0.062,0.061)$ & 0.0625 \\
\hline a3 & $(0.897,0.939,0.956)$ & $(0.053,0.055,0.056)$ & 0.05475 \\
\hline a4 & $(1.373,1.213,1.151)$ & $(0.081,0.071,0.068)$ & 0.07275 \\
\hline b1 & $(1.337,1.193,1.136)$ & $(0.079,0.07,0.067)$ & 0.0715 \\
\hline b2 & $(0.849,0.91,0.936)$ & $(0.05,0.054,0.055)$ & 0.05325 \\
\hline b3 & $(0.81,0.888,0.92)$ & $(0.048,0.052,0.054)$ & 0.0515 \\
\hline c1 & $(0.804,0.895,0.928)$ & $(0.047,0.053,0.055)$ & 0.052 \\
\hline c2 & $(0.843,0.914,0.94)$ & $(0.05,0.054,0.055)$ & 0.05325 \\
\hline d1 & $(1.493,1.283,1.199)$ & $(0.088,0.075,0.071)$ & 0.07725 \\
\hline d2 & $(1.053,1.032,1.023)$ & $(0.062,0.061,0.06)$ & 0.061 \\
\hline d3 & $(1.412,1.23,1.161)$ & $(0.083,0.072,0.068)$ & 0.07375 \\
\hline d4 & $(1.106,1.061,1.043)$ & $(0.065,0.062,0.061)$ & 0.0625 \\
\hline e1 & $(0.455,0.675,0.767)$ & $(0.027,0.04,0.045)$ & 0.038 \\
\hline e2 & $(0.918,0.958,0.972)$ & $(0.054,0.056,0.057)$ & 0.05575 \\
\hline e3 & $(0.679,0.818,0.872)$ & $(0.04,0.048,0.051)$ & 0.04675 \\
\hline e4 & $(0.737,0.854,0.898)$ & $(0.043,0.05,0.053)$ & 0.049 \\
\hline & & & \\
\hline
\end{tabular}

Results from stage 3 :

Ten experts use the lingual variables to evaluate the relative performance of each alternative regarding to each criterion. Then the linguistic variables were converted to triangular fuzzy numbers (see average of all experts in Appendix B). After that average of all judgments calculated and by using the weights of criteria was obtained in stage 2, fuzzy VIKOR method was employed to sorting alternatives based on $\mathrm{S}, \mathrm{R}$ and $\mathrm{Q}$ values and is shown in Table 9. According to Table 9, the performance of alternative 2 "upgrading the existing highway to an elevated highway" is better than alternative 1 "Constructing new urban expressway". First condition "Acceptable Advantage" is satisfied based on following equation:

$$
\begin{gathered}
D Q=\frac{1}{j-1}=\frac{1}{2-1}=1 \\
Q(A 2)-Q(A 1)=2.463-1.302=1.161>D Q=1 .
\end{gathered}
$$

The values of two main parameter $S^{\text {def }}$ and $Q^{\text {def }}$ for alternative 1 are 0.215 and 2.463, which are bigger than same parameter scores for alternative 2 as 0.029 for $S^{\text {def }}$ value and 1.302 for $\mathrm{Q}^{\mathrm{def}}$ value. So the second condition "Acceptable Stability in decision making” is satisfied. The main reason behind this result is the urban land acquisition criterion which was a cause factor based on results of stage 1 and it is because land acquisition in constructing new expressway or extending an existent one play a vital role in urban environment because it increases costs of construction, which is including costs of buying buildings and lands and costs of demolition of existing buildings in order to preparing massive space for construction of urban expressway. In alternative two, construction grows upside of the existing expressway, therefore, this alternative does not demand massive land for developing.

\section{Discussion}

The proposed hybrid MCDM model should be suitable for evaluating performances of alternatives of environmental impact's assessment. The influential relationship of criteria was found by using the fuzzy DEMATEL method. Results of the fuzzy DEMATEL method based on ANP procedure were applied so the weights of criteria were calculated, and it is used in the fuzzy VIKOR method to find out optimum alternative. In this paper, the proposed hybrid MCDM model contains some properties as follows:

This paper used the fuzzy DEMATEL method, which is worked with fuzzy logic. The main advantage of fuzzy logic is the opportunity for using linguistics' variable instead of crisp values which in many fields crisp values are inadequate in the real world and substitution crisp values with linguistics' variables (when preferences are unclear and vague) makes results closer to real-world circumstances. By using the fuzzy DEMATEL method in this paper the cause/effect groups were found, and network relationship map was drawn so importance level and role of each criterion would be presented. Based on weights calculated by using ANP procedure combined with the DEMATEL method, weights and importance of each criterion could be found. In this paper, the empirical study the difference of each criteria weight is not significant (shown in Table 8). Using the fuzzy DEMATEL can show dependency among criteria and cause/effect role of each criterion so according to its results; decision makers can find priority for mitigation of each criterion environmental impacts on urban environment. For example, “Air pollution” and "Safety and Security" are the most important influential criteria (as 0.518 and 0.504) for environmental impacts' assessment of urban expressway and top of that dimension which has the strongest role in EIA of urban expressway is the dimension "E Physical and chemical environment" with the highest score of $\mathrm{D}+\mathrm{R}$ and $\mathrm{D}-\mathrm{R}$ at 15.698 and 2.421, so urban managers can significantly reduce 
environmental impacts of urban expressway by measuring and mitigation adverse impacts of criteria "e1" to "e4" under dimension "E Physical and chemical environment". In the final step of the proposed model of this paper, using the fuzzy VIKOR method provides an opportunity to check whether the best alternative can be considered better enough than the others by testing satisfaction of acceptability advantage and acceptable stability conditions. Furthermore, results of the proposed hybrid model compared with traditional models (TOPSIS and SAW) and the results are consisted. By using materials of this proposed hybrid model in TOPSIS method, performance of each alternative calculated and final scores for alternative 1 and 2 are 0.109 and 0.891 , which is shown alternative 2 better than alternative 1 and the results by using Simple Additive Weighting method for alternative 1 and 2 are 0.780 and 0.971 , which means alternative 2 is better than alternative 1 . The results from TOPSIS and SAW is consistent with results from the proposed model so as all things considered, the hybrid MCDM model is a useful and reasonable tool for evaluating alternatives in EIA of urban expressway.

Table 9. Performance values combined with the influential weights of the criteria according to the DANP.

\begin{tabular}{|c|c|c|c|c|c|c|c|}
\hline Dimension & criteria & $\tilde{p}_{J}^{*}$ & $\tilde{p}_{J}^{\wedge}$ & $\widetilde{w}_{j}$ & $\tilde{d}_{i j}$ & $\tilde{S}_{i}$ & $\tilde{R}_{i}$ \\
\hline \multirow{4}{*}{$\begin{array}{c}\text { Social } \\
\text { environment }\end{array}$} & (a1) & $(2.4,4.2,6.1)$ & $(2.1,4,5.9)$ & $(0.066,0.063,0.062)$ & $(0,0,0)$ & $(0,0,0)$ & $(0.058,0.063,0.056$ \\
\hline & (a2) & $(7.4,9,9.8)$ & $(0,0.6,2.2)$ & $(0.065,0.062,0.061)$ & $(0.889,1.009,0.913)$ & $(0.058,0.063,0.056)$ & $\tilde{S}_{t}$ \\
\hline & (a3) & $(3,4.7,6.5)$ & $(2.3,4.2,6.2)$ & $(0.053,0.055,0.056)$ & $(0.091,0.065,0.039)$ & $(0.005,0.004,0.002)$ & $(0.189,0.225,0.221)$ \\
\hline & (a4) & $(1.9,3.6,5.6)$ & $(1.6,3,4.8)$ & $(0.081,0.071,0.068)$ & $(0.054,0.107,0.143)$ & $(0.004,0.008,0.01)$ & $\tilde{S}^{*}$ \\
\hline \multirow{3}{*}{$\begin{array}{c}\text { Spatial } \\
\text { environment }\end{array}$} & (b1) & $(2.3,3.8,5.5)$ & $(1.2,2.7,4.6)$ & $(0.079,0.07,0.067)$ & $(0.153,0.153,0.125)$ & $(0.012,0.011,0.008)$ & $(0,0,0)$ \\
\hline & (b2) & $(4.6,6.6,8.4)$ & $(3.5,5.4,7.3)$ & $(0.05,0.054,0.055)$ & $(0,0,0)$ & $(0,0,0)$ & $\tilde{S}_{u}^{\wedge}$ \\
\hline & (b3) & $(8,9.5,10)$ & $(0,0.3,1.6)$ & $(0.048,0.052,0.054)$ & $(0.961,1.105,1.009)$ & $(0.046,0.057,0.054)$ & $(0.056,0.056,0.056$ \\
\hline \multirow{2}{*}{$\begin{array}{c}\text { Visual } \\
\text { environment }\end{array}$} & $\left(c_{1}\right)$ & $(3,4.8,6.6)$ & $(2.1,3.7,5.6)$ & $(0.047,0.053,0.055)$ & $(0.163,0.199,0.181)$ & $(0.008,0.011,0.01)$ & $\tilde{S}_{l}^{*}$ \\
\hline & $\left(c_{2}\right)$ & $(2.2,3.9,5.8)$ & $(1.8,3.6,5.5)$ & $(0.05,0.054,0.055)$ & $(0,0,0)$ & $(0,0,0)$ & $(0,0,0)$ \\
\hline \multirow{4}{*}{$\begin{array}{l}\text { Economic } \\
\text { environment }\end{array}$} & (d1) & $(4,6,7.9)$ & $(3.4,5.4,7.4)$ & $(0.088,0.075,0.071)$ & $(0.108,0.108,0.09)$ & $(0.01,0.008,0.006)$ & $\tilde{R}_{l}^{*}$ \\
\hline & (d2) & $(4.2,6.2,8)$ & $(3.5,5.4,7.3)$ & $(0.062,0.061,0.06)$ & $(0,0,0)$ & $(0,0,0)$ & $(0.01,0.01,0.01)$ \\
\hline & (d3) & $(5 \cdot 6,7.2,8.8)$ & $(5.2,7.2,8.3)$ & $(0.083,0.072,0.068)$ & $(0,0,0.099)$ & $(0,0,0.007)$ & $\tilde{R}^{*}$ \\
\hline & (d4) & $(4.2,5.6,6.8)$ & $(3.7,5,6.2)$ & $(0.065,0.062,0.061)$ & $(0.068,0.082,0.082)$ & $(0.004,0.005,0.005)$ & $(0.01,0.012,0.011)$ \\
\hline \multirow{4}{*}{$\begin{array}{l}\text { Physical and } \\
\text { chemical } \\
\text { environment }\end{array}$} & $\left(\mathrm{e}_{1}\right)$ & $(3,4.8,6.7)$ & $(1.9,3.4,5.3)$ & $(0.027,0.04,0.045)$ & $(0.222,0.283,0.283)$ & $(0.006,0.011,0.013)$ & $\tilde{R}_{u}^{\wedge}$ \\
\hline & $\left(\mathrm{e}_{2}\right)$ & $(3.7,5.6,7.5)$ & $(3,4.8,6.7)$ & $(0.054,0.056,0.057)$ & $(0.127,0.145,0.145)$ & $(0.007,0.008,0.008)$ & $(0.056,0.056,0.056)$ \\
\hline & $\left(\mathrm{e}_{3}\right)$ & $(3.3,5.2,7)$ & $(2.9,4.8,6.7)$ & $(0.04,0.048,0.051)$ & $(0,0,0)$ & $(0,0,0)$ & $\tilde{Q}$ \\
\hline & $\left(\mathrm{e}_{4}\right)$ & $(5,7,8.7)$ & $(0.8,2,3.8)$ & $(0.043,0.05,0.053)$ & $(0.676,0.805,0.789)$ & $(0.029,0.04,0.042)$ & $(2.217,2.579,2.476)$ \\
\hline Dimension & criteria & $R_{i}^{\text {def }}$ & $\tilde{d}_{i j}$ & $\tilde{S}_{i}$ & $\tilde{R}_{i}$ & $R_{i}^{\text {def }}$ & \\
\hline \multirow{4}{*}{$\begin{array}{c}\text { Social } \\
\text { environment }\end{array}$} & (a1) & 0.060 & $(0.037,0.025,0.025)$ & $(0.002,0.002,0.002)$ & $(0.01,0.012,0.011)$ & 0.011 & \\
\hline & (a2) & $S_{t}^{\text {def }}$ & $(0,0,0)$ & $(0,0,0)$ & $\tilde{S}_{t}$ & $S_{t}^{\text {def }}$ & \\
\hline & (a3) & 0.215 & $(0,0,0)$ & $(0,0,0)$ & $(0.034,0.029,0.026)$ & 0.029 & \\
\hline & (a4) & $S^{* d e f}$ & $(0,0,0)$ & $(0,0,0)$ & $\tilde{S}^{*}$ & $S^{* d e f}$ & \\
\hline \multirow{3}{*}{$\begin{array}{c}\text { Spatial } \\
\text { environment }\end{array}$} & (b1) & 0 & $(0,0,0)$ & $(0,0,0)$ & $(0,0,0)$ & 0 & \\
\hline & (b2) & $S_{u}^{\wedge} \operatorname{def}$ & $(0.204,0.223,0.204)$ & $(0.01,0.012,0.011)$ & $\tilde{S}_{u}^{\wedge}$ & $S_{u}^{\wedge \text { def }}$ & \\
\hline & (b3) & 0.056 & $(0,0,0)$ & $(0,0,0)$ & $(0.011,0.011,0.011)$ & 0.011 & \\
\hline \multirow{2}{*}{$\begin{array}{c}\text { Visual } \\
\text { environment }\end{array}$} & $\left(c_{1}\right)$ & $S_{l}^{* \operatorname{def}}$ & $(0,0,0)$ & $(0,0,0)$ & $\tilde{S}_{l}^{*}$ & $S_{l}^{* \operatorname{def}}$ & \\
\hline & $\left(c_{2}\right)$ & 0 & $(0.073,0.055,0.055)$ & $(0.004,0.003,0.003)$ & $(0,0,0)$ & 0.000 & \\
\hline \multirow{4}{*}{$\begin{array}{l}\text { Economic } \\
\text { environment }\end{array}$} & (d1) & $R_{l}^{* d e f}$ & $(0,0,0)$ & $(0,0,0)$ & $\tilde{R}_{l}^{*}$ & $R_{l}^{* d e f}$ & \\
\hline & (d2) & 0.01 & $(0.133,0.152,0.133)$ & $(0.008,0.009,0.008)$ & $(0.01,0.01,0.01)$ & 0.01 & \\
\hline & $(\mathrm{d} 3)$ & $R^{* d e f}$ & $(0.079,0,0)$ & $(0.007,0,0)$ & $\tilde{R}^{*}$ & $R^{* d e f}$ & \\
\hline & $(\mathrm{d} 4)$ & 0.011 & $(0,0,0)$ & $(0,0,0)$ & $(0.01,0.012,0.011)$ & 0.011 & \\
\hline \multirow{4}{*}{$\begin{array}{l}\text { Physical and } \\
\text { chemical } \\
\text { environment }\end{array}$} & $\left(e_{1}\right)$ & $R_{u}^{\wedge d e f}$ & $(0,0,0)$ & $(0,0,0)$ & $\tilde{R}_{u}^{\wedge}$ & $R_{u}^{\wedge \text { def }}$ & \\
\hline & $\left(e_{2}\right)$ & 0.056 & $(0,0,0)$ & $(0,0,0)$ & $(0.056,0.056,0.056)$ & 0.056 & \\
\hline & $\left(\mathrm{e}_{3}\right)$ & $Q^{\text {def }}$ & $(0.06,0.06,0.045)$ & $(0.002,0.003,0.002)$ & $\tilde{Q}$ & $Q^{d e f}$ & \\
\hline & $\left(\mathrm{e}_{4}\right)$ & 2.463 & $(0,0,0)$ & $(0,0,0)$ & $(1.492,1.278,1.16)$ & 1.302 & \\
\hline
\end{tabular}




\section{Conclusion}

This paper combined several methods to propose the hybrid MCDM model which is adopted with real-world circumstances and to make proposed model much closer to reality. Based on the results of empirical study the hybrid MCDM model should be a reliable and pragmatic model to assessing alternatives performances regarding environmental impact assessment of urban expressways and to demonstrate the inner-relations among criteria. Although the main negative point of this hybrid model is its complexity in using for evaluation process, but compared to traditional methods used for evaluating alternatives in EIA, this model considers interrelations based on network relations map so if a project of urban expressway is deficient in environmental impacts this model could find out the most important dimensions for measuring and mitigation in later steps of EIA. This model also could find out the suitable alternative which is closest solution to the ideal scenario. We hope that results of this article help decision-makers to decide which alternative is the best solution in a way that would be more reliable and much closer to reality.

\section{References}

[1] Kates, R. W., Parris, T. M., \& Leiserowitz, A. A. (2005). Achieving Sustainable Development and Promoting Development Cooperation. Environment: Science and Policy for Sustainable Development, 47.

[2] Ogola, P. F. A. (2007). ENVIRONMENTAL IMPACT ASSESSMENT GENERAL PROCEDURES. KenGen, 2-17.

[3] Overseas Environmental Cooperation Center. (2000). Environmental Impact Assessment for International Cooperation. Japan: Environment Agency of Government of Japan.

[4] Lohani, B., Evans, J. W., Ludwig, H., Richard, A., \& Tu, S. L. (1997). Environmental Impact Assessment for Developing Countries in Asia (Vol. 1): Asia Development Bank.

[5] Rao, S. K. (2010). Environmental Impact Assessment Guidance Manual for Highways. Hyderabad: Administrative Staff College of India.

[6] Lahdelma, R., \& Salminen, P. (2009). Ordinal Measurements with Interval Constraints in the EIA Process for Siting a Waste Storage Area. NATO Science for Peace and Security Series C: Environmental Security, 397-413.

[7] Ramanathan, R. (2001). A note on the use of the analytic hierarchy process for environmental impact assessment. Journal of Environmental Management(63), 27-35.

[8] Dimitrios Tsamboulas, \& Mikroudis, G. (2000). EFECT_evaluation framework of environmental impacts and costs of transport initiatives. Transportation Research Part D, 283-303.

[9] Robert Handfield, Steven V. Walton, Robert Sroufe, \& Melnyk, S. A. (2002). Applying environmental criteria to supplier assessment: A study in the application of the Analytical Hierarchy Process. European Journal of Operational Research(141), 70-87.

[10] E. Fontela, \& Gabus, A. (1974). DEMATEL, innovative methods: Battelle Geneva Research Institute.

[11] Barrow, C. J. (1997). Environmental and social impact assessment: an introduction. London: Arnold, Hodder Headline, PLC.

[12] Gilpin, A. (1995). Environmental impact assessment (EIA): cutting edge for the twenty-first century. Cambridge: Cambridge University Press.

[13] Maclean, I., Macken, K., Byrne, G., O’Mahony, T., \& Archer, B. (2002). Guidelines on the information to be contained in Environmental Impact Statements. Ireland: Environmental Protection Agency,.

[14] Shopley, J. B., \& Fuggle, R. F. (1984). Comprehensive review of current environmental impact assessment methods and techniques. Journal of Environmental Management, 18:1.
[15] Beanlands, G. E., \& Duinker, P. N. (1984). Ecological framework for environmental impact assessment. Journal of Environmental Management, 18:3.

[16] Brouwer, R., \& Ek, R. V. (2004). Integrated ecological, economic and social impact assessment of alternative flood control policies in the Netherlands. Ecological Economics, 50, 1-21.

[17] Vanclay, F., \& Bronstein, D. A. (1995). Environmental and social impact assessment. Chichester: John Wiley \& Sons.

[18] Yunhui, Q., Shuwang, W., Junqi, P., Zhifeng, L., \& Hongchao, Z. Environmental Impact Assessment Method Based Synthesis Weight. National Natural Science Foundation of China.

[19] Daniel, S. E., Tsoulfas, G. T., Pappis, C. P., \& Rachaniotis, N. P. (2004). Aggregating and evaluating the results of different Environmental Impact Assessment methods. Ecological Indicators, 4, 125-138.

[20] Hongling, Q., Suimin, M., \& Xincong, Z. (2010). Environmental Impact Assessment of Artificial Aggregate Systems Based on Fuzzy Comprehensive Evaluation. Paper presented at the International Conference on Challenges in Environmental Science and Computer Engineering, China.

[21] Balasubramaniam, A., \& Voulvoulis, N. (2005). The Appropriateness of Multicriteria Analyisis in Environmental Decision-Making Problems. Environmental Technology, 26(9), 951-962.

[22] Boufateh, I., Perwuelz, A., Rabenasolo, B., \& Jolly, A.-M. (2012). Multiple Criteria Decision Making for environmental impacts optimization. International Journal of Business Performance and Supply Chain Modelling, 3(1), 28-42.

[23] Broughtona, E. K., Brenta, A. C., \& Haywoodc, L. (2008). APPLICATION OF A MULTI-CRITERIA ANALYSIS APPROACH FOR DECISION-MAKING IN THE ENERGY SECTOR: THE CASE OF CONCENTRATING SOLAR POWER IN SOUTH AFRICA. Energy and Environment, 23.

[24] Geldermann, J., Zhang, K., \& Rentz, O. (2005). Multi-criteria group decision support for integrated technique assessment. French-German Institute for Environmental Research

[25] Omann, I. (2001). How can Multi-criteria Decision Analysis contribute to environmental policy making? A case study on macro-sustainability in Germany. Paper presented at the Third International Conference of the European Society for Ecological Economics, Vienna, Austria.

[26] Rahman, M. A., Rusteberg, B., Uddin, M. S., Saada, M. A., Rabi, A., \& Sauter, M. (2014). Impact Assessment and Multicriteria Decision Analysis of Alternative Managed Aquifer Recharge Strategies Based on Treated Wastewater in Northern Gaza. water, 6.

[27] Sagbas, A., \& Mazmanoglu, A. (2014). Use of multicriteria decision analysis to assess alternative wind power plants. Journal of Engg. Research, 2(1), 147-161.

[28] Linkov, I., Satterstrom, F. K., Steevens, J., Ferguson, E., \& Pleus, R. C. (2007). Multi-criteria decision analysis and environmental risk assessment for nanomaterials. Journal of Nanoparticle Research, 9.

[29] Linkov, I., Varghese, A., \& Jamil, S. (2004). Multi-criteria Decision Analysis: A Framework for Structuring Remedial Decisions at Contaminated Sites. Comparative Risk Assessment and Environmental Decision Making, 15-54.

[30] Wu, K., \& Zhang, L. (2014). Progress in the Development of Environmental Risk Assessment as a Tool for the DecisionMaking Process. Journal of Service Science and Management, 7, 131-143.

[31] Boclin, A. d. S. C., \& de, M. R. (2006). A decision support method for environmental impact assessment using a fuzzy logic approach. Ecological Economics, 58(1), 170-181.

[32] Chang, N. B., Chen, H. W., \& Ning, S. K. (2001). Identification of river water quality using the fuzzy synthetic evaluation approach. Journal of Environmental Management, 63(3), 293-305.

[33] Contreras, F., Hanaki, K., Aramaki, T., \& Connors, S. (2008). Application of analytical hierarchy process to analyze stakeholders preferences for municipal solid waste management plans. Resources Conservation and Recycling, 52, 979-991.

[34] Liu, K. F. R., Hsu, C.-Y., Yeh, K., \& Chen, C.-W. (2011). Hierarchical analytic network process and its application in environmental impact evaluation. Civil Engineering and Environmental Systems, 28(1), 1-18.

[35] Liu, K. F. R., \& Lai, J. H. (2009). Decision-support for environmental impact assessment: A hybrid approach using fuzzy 
logic and fuzzy analytic network process. Expert Systems with Applications, 36, 5119-5136.

[36] Evans, R. (2012). Decision Making in the Environmental Impact Assessment Process. U.S. Nuclear Regulatory Commission.

[37] Wang, Y.-M., Yang, J.-B., \& Xu, D.-L. (2004). Environmental impact assessment using the evidential reasoning approach. European Journal of Operational Research(174).

[38] Kevin F.R. Liu, \& Lai, J.-H. (2009). Decision-support for environmental impact assessment: A hybrid approach using fuzzy logic and fuzzy analytic network process. Expert Systems with Applications(36).

[39] Carter Burgess. (2008). I-70B West Environmentla Assessment. Colorado.

[40] Colorado Department of Transportation. (2006). Valley Highway Logan to 6th Ave. Final Evnironmental Impact Statement. Colorado.

[41] Economic Reconstruction Agency. (January 2012). Jammu and Kashmir Urban Sector Development Investment ProgramConstruction of Elevated Expressway Corridor (Flyover) from Jehangir Chowk to Rambagh and Natipora in Srinagar City (pp. 125). Kashmir.

[42] Michigan Department of Transportation. (2013). US-31 Environmental Impact Statement. Michigan, USA.

[43] Viet Nam Expressway Corporation. (2010). Viet Nam: GMS Ben Luc - Long Thanh Expressway Project (Multi-tranche Financing Facility) Environmental Assessment Report. Viet Nam.

[44] Vietnam Expressway Corporation. (October 2011). Initial Environmental Examination for Ho Chi Minh City - Long Thanh Dau Giay Expressway Project 2374-VIE: Ministry of Transport of VietNam.

[45] Yang, Y.-P. O., Shieh, H.-M., \& Tzeng, G.-H. (2013). A VIKOR technique based on DEMATEL and ANP for information security risk control assessment. Information Sciences, 232.

[46] Hsu, C.-H., Wang, F.-K., \& Tzeng, G.-H. (2012). The best vendor selection for conducting the recycled material based on a hybrid MCDM model combining DANP with VIKOR. Resources, Conservation and Recycling, 66.

[47] Chiu, W. Y., Tzeng, G. H., \& Li, H. L. (2013). A new hybrid MCDM model combining DANP with VIKOR to improve e-store business. Knowledge-Based Systems, 37.

[48] Wang, Y.-L., \& Tzeng, G.-H. (2012). Brand marketing for creating brand value based on a MCDM model combining DEMATEL with ANP and VIKOR methods. Expert Systems with Applications, 39.
[49] Mei-Tai Chu, Joseph Shyu, Gwo-Hshiung Tzeng, \& Khosla, R. (2007). Comparison among three analytical methods for knowledge communities group-decision analysis. Expert Systems with Applications (33).

[50] Ningxia Environmental Protection, Department. (December/ 2009) Environmental Impact Assessment Executive Summary. China.

[51] Economic Reconstruction Agency. (2012). Jammu and Kashmir Urban Sector Development Investment Program-Construction of Elevated Expressway Corridor (Flyover) from Jehangir Chowk to Rambagh and Natipora in Srinagar City Initial Environmental Examination.

[52] Modi, A., \& Shinkar, N. P. (2012). Environmental Impact Assessment of Road from Ujjain to Jaora. International Journal of Engineering and Advanced Technology, 1(4).

[53] Kaya, T., \& Kahraman, C. (2011). An integrated fuzzy AHPELECTRE methodology for environmental impact assessment. Expert Systems with Applications, 38.

[54] Lohani, B. N., Evans, J. W., Everitt, R. R., Ludwig, H., Carpenter, R. A., \& Tu, S.-L. (1997). Environmental Impact Assessment for Developing Countries in Asia (Vol. 1): Asian Developement Bank

[55] National Highway Authority. (July 2007). Islamic Republic of Pakistan: National Trade Corridor Highway Investment Program Faisalabad-Khanewal Expressway (E-4)(184 Km) (pp. 147).

[56] TRANSJAMAICAN HIGHWAY, LTD. (September, 2007). Environmental Impact Assessment Highway 2000: Phase 1B Sandy Bay to Williamsfield Km: 33+000 to 71+500. Kingston.

[57] Viet Nam Expressway Corporation. (September 2010). Viet Nam: GMS Ben Luc - Long Thanh Expressway Project (Multi-tranche Financing Facility).

[58] A. Felix, \& Devadoss, A. V. (2014). A Fuzzy DEMATELTrapezoidal Structure for Modeling Cause and Effect Relationships of Youth Violence. International Journal of Computing Algorithm, 3, 474-483.

[59] Javad Jassbi, Farshid Mohamadnejad, \& Nasrollahzadeh, H. (2011). A Fuzzy DEMATEL framework for modeling cause and effect relationships of strategy map. Expert Systems with Applications(38), 5967-5973.

[60] Li Chung-Wei, \& Gwo-Hshiung, T. (2009). Identification of a Threshold Value for the DEMATEL Method: Using the Maximum Mean De-Entropy Algorithm Cutting-Edge Research Topics on Multiple Criteria Decision Making (pp. 789-796): Springer Berlin Heidelberg.

[61] Shankar Chakrabortya, \& Chatterjee, P. (2013). Selection of materials using multi-criteria decision-making methods with minimum data. Decision Science Letters, 2, 135-148.

\section{Appendix A}

Table A1. Average of all experts' judgments for the fuzzy DEMATEL method based on questioner 1

\begin{tabular}{|c|c|c|c|c|c|c|}
\hline Criteria & $\mathrm{a} 1$ & $\mathrm{a} 2$ & $\mathrm{a} 3$ & $\mathrm{a} 4$ & $\mathrm{~b} 1$ & $\mathrm{~b}$ \\
\hline $\mathrm{a} 1$ & $(0,0,0)$ & $(0.24,0.44,0.64)$ & $(0.08,0.28,0.48)$ & $(0.4,0.6,0.8)$ & $(0.28,0.48,0.68)$ & $(0.24,0.44,0.64)$ \\
\hline $\mathrm{a} 2$ & $(0.36,0.56,0.76)$ & $(0,0,0)$ & $(0.2,0.4,0.6)$ & $(0.4,0.6,0.8)$ & $(0.36,0.56,0.76)$ & $(0.2,0.4,0.6)$ \\
\hline a3 & $(0.52,0.72,0.92)$ & $(0.4,0.6,0.8)$ & $(0,0,0)$ & $(0.44,0.64,0.84)$ & $(0.36,0.56,0.76)$ & $(0.24,0.44,0.64)$ \\
\hline a4 & $(0.2,0.4,0.6)$ & $(0.2,0.4,0.6)$ & $(0.16,0.36,0.56)$ & $(0,0,0)$ & $(0.28,0.48,0.68)$ & $(0.2,0.4,0.6)$ \\
\hline b1 & $(0.32,0.52,0.72)$ & $(0.24,0.44,0.64)$ & $(0.24,0.44,0.64)$ & $(0.32,0.52,0.72)$ & $(0,0,0)$ & $(0.2,0.4,0.6)$ \\
\hline b2 & $(0.36,0.56,0.76)$ & $(0.4,0.6,0.8)$ & $(0.36,0.56,0.76)$ & $(0.4,0.6,0.8)$ & $(0.4,0.6,0.8)$ & $(0,0,0)$ \\
\hline b3 & $(0.36,0.56,0.76)$ & $(0.44,0.64,0.84)$ & $(0.32,0.52,0.72)$ & $(0.48,0.68,0.88)$ & $(0.4,0.6,0.8)$ & $(0.28,0.48,0.68)$ \\
\hline c1 & $(0.44,0.64,0.84)$ & $(0.32,0.52,0.72)$ & $(0.32,0.52,0.72)$ & $(0.56,0.76,0.96)$ & $(0.4,0.6,0.8)$ & $(0.28,0.48,0.68)$ \\
\hline c2 & $(0.36,0.56,0.76)$ & $(0.32,0.52,0.72)$ & $(0.28,0.48,0.68)$ & $(0.52,0.72,0.92)$ & $(0.4,0.6,0.8)$ & $(0.28,0.48,0.68)$ \\
\hline d1 & $(0.16,0.36,0.56)$ & $(0.2,0.4,0.6)$ & $(0.12,0.32,0.52)$ & $(0.24,0.44,0.64)$ & $(0.24,0.44,0.64)$ & $(0.2,0.4,0.6)$ \\
\hline d2 & $(0.24,0.44,0.64)$ & $(0.36,0.56,0.76)$ & $(0.2,0.4,0.6)$ & $(0.4,0.6,0.8)$ & $(0.44,0.64,0.84)$ & $(0.16,0.36,0.56)$ \\
\hline d3 & $(0.12,0.32,0.52)$ & $(0.24,0.44,0.64)$ & $(0.24,0.44,0.64)$ & $(0.280 .480 .68)$ & $(0.28,0.48,0.68)$ & $(0.08,0.28,0.48)$ \\
\hline d4 & $(0.32,0.52,0.72)$ & $(0.28,0.48,0.68)$ & $(0.32,0.52,0.72)$ & $(0.36,0.56,0.76)$ & $(0.44,0.64,0.84)$ & $(0.12,0.32,0.52)$ \\
\hline e1 & $(0.48,0.68,0.88)$ & $(0.52,0.72,0.92)$ & $(0.48,0.68,0.88)$ & $(0.48,0.68,0.88)$ & $(0.48,0.68,0.88)$ & $(0.44,0.64,0.84)$ \\
\hline e2 & $(0.36,0.56,0.76)$ & $(0.36,0.56,0.76)$ & $(0.28,0.48,0.68)$ & $(0.36,0.56,0.76)$ & $(0.52,0.72,0.92)$ & $(0.36,0.56,0.76)$ \\
\hline e3 & $(0.48,0.68,0.88)$ & $(0.4,0.6,0.8)$ & $(0.36,0.56,0.76)$ & $(0.44,0.64,0.84)$ & $(0.56,0.76,0.96)$ & $(0.36,0.56,0.76)$ \\
\hline e4 & $(0.36,0.56,0.76)$ & $(0.4,0.6,0.8)$ & $(0.32,0.52,0.72)$ & $(0.48,0.68,0.88)$ & $(0.56,0.76,0.96)$ & $(0.4,0.6,0.8)$ \\
\hline
\end{tabular}




\begin{tabular}{|c|c|c|c|c|c|c|}
\hline Criteria & b3 & $\mathrm{c1}$ & c2 & $\mathrm{d} 1$ & $\mathrm{~d} 2$ & $\mathrm{~d} 3$ \\
\hline a1 & $(0.24,0.44,0.64)$ & $(0.16,0.36,0.56)$ & $(0.24,0.44,0.64)$ & $(0.44,0.64,0.84)$ & $(0.36,0.56,0.76)$ & $(0.48,0.68,0.88)$ \\
\hline $\mathrm{a} 2$ & $(0.16,0.36,0.56)$ & $(0.28,0.48,0.68)$ & $(0.28,0.48,0.68)$ & $(0.4,0.6,0.8)$ & $(0.24,0.44,0.64)$ & $(0.36,0.56,0.76)$ \\
\hline a3 & $(0.28,0.48,0.68)$ & $(0.28,0.48,0.68)$ & $(0.32,0.52,0.72)$ & $(0.48,0.68,0.88)$ & $(0.4,0.6,0.8)$ & $(0.36,0.56,0.76)$ \\
\hline $\mathrm{a} 4$ & $(0.12,0.32,0.52)$ & $(0.04,0.24,0.44)$ & $(0.08,0.28,0.48)$ & $(0.36,0.56,0.76)$ & $(0.2,0.4,0.6)$ & $(0.32,0.52,0.72)$ \\
\hline b1 & $(0.2,0.4,0.6)$ & $(0.2,0.4,0.6)$ & $(0.2,0.4,0.6)$ & $(0.36,0.56,0.76)$ & $(0.16,0.36,0.56)$ & $(0.32,0.52,0.72)$ \\
\hline b2 & $(0.32,0.52,0.72)$ & $(0.32,0.52,0.72)$ & $(0.32,0.52,0.72)$ & $(0.4,0.6,0.8)$ & $(0.44,0.64,0.84)$ & $(0.52,0.72,0.92)$ \\
\hline b3 & $(0,0,0)$ & $(0.32,0.52,0.72)$ & $(0.32,0.52,0.72)$ & $(0.48,0.68,0.88)$ & $(0.32,0.52,0.72)$ & $(0.44,0.64,0.84)$ \\
\hline $\mathrm{c} 1$ & $(0.28,0.48,0.68)$ & $(0,0,0)$ & $(0.28,0.48,0.68)$ & $(0.52,0.72,0.92)$ & $(0.44,0.64,0.84)$ & $(0.48,0.68,0.88)$ \\
\hline c2 & $(0.28,0.48,0.68)$ & $(0.32,0.52,0.72)$ & $(0,0,0)$ & $(0.48,0.68,0.88)$ & $(0.44,0.64,0.84)$ & $(0.48,0.68,0.88)$ \\
\hline $\mathrm{d} 1$ & $(0.12,0.32,0.52)$ & $(0.08,0.28,0.48)$ & $(0.12,0.32,0.52)$ & $(0,0,0)$ & $(0.16,0.36,0.56)$ & $(0.28,0.48,0.68)$ \\
\hline $\mathrm{d} 2$ & $(0.28,0.48,0.68)$ & $(0.16,0.36,0.56)$ & $(0.16,0.36,0.56)$ & $(0.44,0.64,0.84)$ & $(0,0,0)$ & $(0.4,0.6,0.8)$ \\
\hline $\mathrm{d} 3$ & $(0.16,0.36,0.56)$ & $(0.12,0.32,0.52)$ & $(0.12,0.32,0.52)$ & $(0.32,0.52,0.72)$ & $(0.2,0.4,0.6)$ & $(0,0,0)$ \\
\hline $\mathrm{d} 4$ & $(0.24,0.44,0.64)$ & $(0.2,0.4,0.6)$ & $(0.2,0.4,0.6)$ & $(0.4,0.6,0.8)$ & $(0.2,0.4,0.6)$ & $(0.44,0.64,0.84)$ \\
\hline e1 & $(0.44,0.64,0.84)$ & $(0.44,0.64,0.84)$ & $(0.44,0.64,0.84)$ & $(0.52,0.72,0.92)$ & $(0.4,0.6,0.8)$ & $(0.44,0.64,0.84)$ \\
\hline e2 & $(0.2,0.4,0.6)$ & $(0.28,0.48,0.68)$ & $(0.28,0.48,0.68)$ & $(0.48,0.68,0.88)$ & $(0.36,0.56,0.76)$ & $(0.44,0.64,0.84)$ \\
\hline e3 & $(0.24,0.44,0.64)$ & $(0.4,0.6,0.8)$ & $(0.4,0.6,0.8)$ & $(0.52,0.72,0.92)$ & $(0.36,0.56,0.76)$ & $(0.44,0.64,0.84)$ \\
\hline e4 & $(0.28,0.48,0.68)$ & $(0.4,0.6,0.8)$ & $(0.36,0.56,0.76)$ & $(0.52,0.72,0.92)$ & $(0.4,0.6,0.8)$ & $(0.44,0.64,0.84)$ \\
\hline Criteria & $\mathrm{d} 4$ & e1 & e2 & e3 & e4 & \\
\hline a1 & $(0.28,0.48,0.68)$ & $(0.12,0.32,0.52)$ & $(0.24,0.44,0.64)$ & $(0.12,0.32,0.52)$ & $(0.24,0.44,0.64)$ & \\
\hline a2 & $(0.32,0.52,0.72)$ & $(0.08,0.28,0.48)$ & $(0.24,0.44,0.64)$ & $(0.2,0.4,0.6)$ & $(0.2,0.4,0.6)$ & \\
\hline a3 & $(0.28,0.48,0.68)$ & $(0.12,0.32,0.52)$ & $(0.32,0.52,0.72)$ & $(0.24,0.44,0.64)$ & $(0.28,0.48,0.68)$ & \\
\hline a4 & $(0.24,0.44,0.64)$ & $(0.12,0.32,0.52)$ & $(0.24,0.44,0.64)$ & $(0.16,0.36,0.56)$ & $(0.12,0.32,0.52)$ & \\
\hline b1 & $(0.16,0.36,0.56)$ & $(0.12,0.32,0.52)$ & $(0.08,0.28,0.48)$ & $(0.04,0.24,0.44)$ & $(0.04,0.24,0.44)$ & \\
\hline b2 & $(0.48,0.68,0.88)$ & $(0.16,0.36,0.56)$ & $(0.24,0.44,0.64)$ & $(0.24,0.44,0.64)$ & $(0.2,0.4,0.6)$ & \\
\hline b3 & $(0.36,0.56,0.76)$ & $(0.16,0.36,0.56)$ & $(0.4,0.6,0.8)$ & $(0.36,0.56,0.76)$ & $(0.32,0.52,0.72)$ & \\
\hline c1 & $(0.4,0.6,0.8)$ & $(0.16,0.36,0.56)$ & $(0.32,0.52,0.72)$ & $(0.2,0.4,0.6)$ & $(0.2,0.4,0.6)$ & \\
\hline c2 & $(0.4,0.6,0.8)$ & $(0.16,0.36,0.56)$ & $(0.32,0.52,0.72)$ & $(0.2,0.4,0.6)$ & $(0.24,0.44,0.64)$ & \\
\hline $\mathrm{d} 1$ & $(0.2,0.4,0.6)$ & $(0.08,0.28,0.48)$ & $(0.12,0.32,0.52)$ & $(0.08,0.28,0.48)$ & $(0.08,0.28,0.48)$ & \\
\hline $\mathrm{d} 2$ & $(0.4,0.6,0.8)$ & $(0.2,0.4,0.6)$ & $(0.24,0.44,0.64)$ & $(0.24,0.44,0.64)$ & $(0.2,0.4,0.6)$ & \\
\hline $\mathrm{d} 3$ & $(0.16,0.36,0.56)$ & $(0.16,0.36,0.56)$ & $(0.16,0.36,0.56)$ & $(0.16,0.36,0.56)$ & $(0.16,0.36,0.56)$ & \\
\hline $\mathrm{d} 4$ & $(0,0,0)$ & $(0.12,0.32,0.52)$ & $(0.24,0.44,0.64)$ & $(0.2,0.4,0.6)$ & $(0.2,0.4,0.6)$ & \\
\hline e1 & $(0.48,0.68,0.88)$ & $(0,0,0)$ & $(0.56,0.76,0.96)$ & $(0.56,0.76,0.96)$ & $(0.48,0.68,0.88)$ & \\
\hline e2 & $(0.36,0.56,0.76)$ & $(0.04,0.24,0.44)$ & $(0,0,0)$ & $0.16,0.36,0.56)$ & $(0.24,0.44,0.64)$ & \\
\hline e3 & $(0.4,0.6,0.8)$ & $(0.04,0.24,0.44)$ & $(0.44,0.64,0.84)$ & $(0,0,0)$ & $(0.44,0.64,0.84)$ & \\
\hline e4 & $(0.4,0.6,0.8)$ & $(0.12,0.32,0.52)$ & $(0.36,0.56,0.76)$ & $(0.16,0.36,0.56)$ & $(0,0,0)$ & \\
\hline
\end{tabular}

\section{Appendix B}

Table B1. Average of all experts' judgments for VIKOR technique based on questioner 2.

\begin{tabular}{|l|c|c|}
\hline Criteria & Alternative 1 & Alternative 2 \\
\hline (a1) Social justice & $(3.1,5,6.8)$ & $(1.4,3.2,5.2)$ \\
\hline (a2) Relocation of houses & $(3.7,4.7,5.9)$ & $(2,3.7 .6 .2)$ \\
\hline (a3) Safety and Security & $(3.3,5.2,7.1)$ & $(1.3,2.6,4.4)$ \\
\hline (a) Restricted access problems & $(2.2,4,6)$ & $(1.9,3.5,5.3)$ \\
\hline (b1) Public utilities & $(1.6,3,4.8)$ & $(4.6,6.6,8.5)$ \\
\hline (b2) Traffic Management & $(3.5,5.4,7.2)$ & $(3.9,4.9,5.9)$ \\
\hline (b3) Land acquisition & $(4.1,4.9,5.7)$ & $(3.2,5,6.9)$ \\
\hline$\left(\mathrm{c}_{1}\right)$ Aesthetic and architectural values & $(1.9,3.5,5.3)$ & $(2,3.8,5.8)$ \\
\hline$\left(\mathrm{c}_{2}\right)$ Landscape and visual appearance & $(2,3.7,5.5)$ & $(4.2,6.2,8.1)$ \\
\hline$(\mathrm{d} 1)$ Income residents and shopkeepers & $(3.2,5.2,7.2)$ & $(4.5,6.4,8.1)$ \\
\hline$(\mathrm{d} 2)$ Land and real estate prices & $(3.2,5.2,7.2)$ & $(6.2,8,9.1)$ \\
\hline$(\mathrm{d} 3)$ The investment in the region & $(4.6,6.4,8)$ & $(7.2,8.8,9.6)$ \\
\hline$(\mathrm{d} 4)$ Time saving & $(0.7,1.8,3.4)$ & $(2.2,4,5.9)$ \\
\hline$\left(\mathrm{e}_{1}\right)$ Air pollution & $(2.7,4.2,6.1)$ & $(2.8,4.6,6.6)$ \\
\hline$\left(\mathrm{e}_{2}\right)$ Water pollution & $(3.9,5.8,7.6)$ & $(3.5,5.4,7.2)$ \\
\hline$\left(\mathrm{e}_{3}\right)$ Noise pollution & $(2.7,4.6,6.5)$ & $(3.5,5.4,7.2)$ \\
\hline$\left(\mathrm{e}_{4}\right)$ Environmental damage & $(2.3,3.6,5.3)$ & \\
\hline
\end{tabular}

